\title{
نحو نموذج مقترح لبناء التوجهات الاستراتيجية في الجامعات الحكومية السعودية
}

*. دممد أحمد الجيزاوي

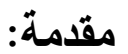

تبدأ مراحل وعمليات الإدارة الاستراتيجية بتحديد الاتجاه الاستراتيجي للمنظمة من خلال ثناثة مداخل يمكن الفصل بينهما بالرغم من تكاملها وترابطها: الأول: يعتمد على تحديد الاتجاه الاستراتيجي من رسالة ورؤية وقيم وأهداف استراتيجية

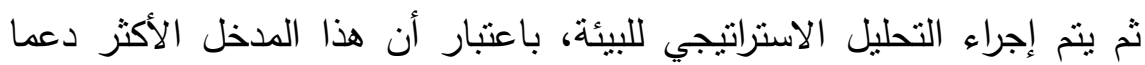

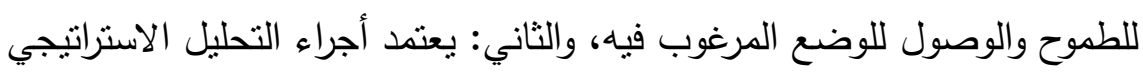
أولا قبل البدء في تحديد التوجهات الاستراتيجية، باعتبار أن هذا المدخل الأكثر واقعية، أما الثالث: فهو يمزج بين المدخلين السابقين، ويرى أن تحديد الاتجاه الاستراتيجي، وتحليل وتقييم البيئة، يفترض أن ينطلقا من نظرة شمولية نكاملية،

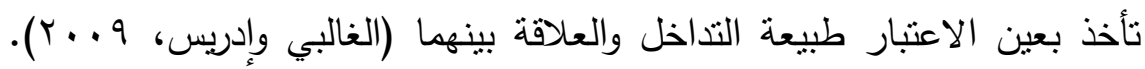
وقد رجحت الدراسة الحالية المدخل الثالث كأسلوب يجمع بين الطموح والواقعية، بئه

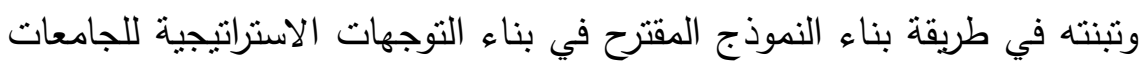

$$
\text { الحكومية السعودية. }
$$

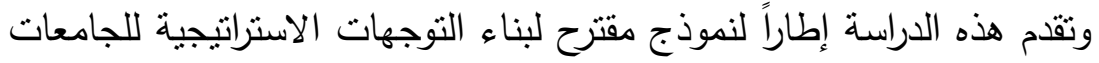
الحكومية السعودية، التي تم اثتقاقها بمنهجية تحليل السلاسل الزمنية على خمس إلى

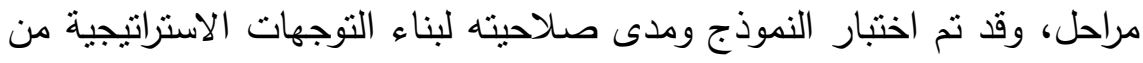

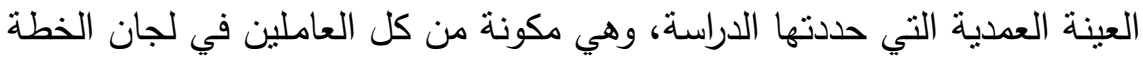
الاستراتيجية الرئيسية والفرعية بجامعة الملك 
فيصل والتي انتهت إلى قبول النموذج المقترح، ومن أهم التوصيات التي قدمتها الدراسة للجامعات الحكومية السعودية ضرورة استتباط التوجهات الاستراتيجية للجامعات الحكومية من المؤشرات المعتمدة عالمياً والتي عبر عنها النموذج بعيداً

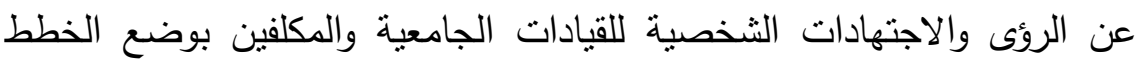
الاستراتيجية، وعدم اللجوء للاجتهاد إلا في حدود ضيقة جداً، مع ضرورة الاهتمام

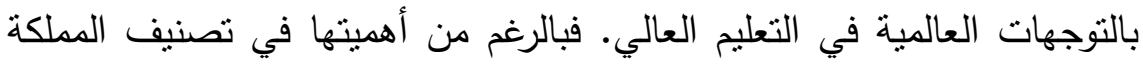

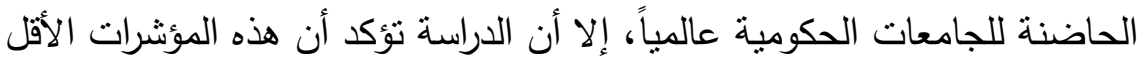

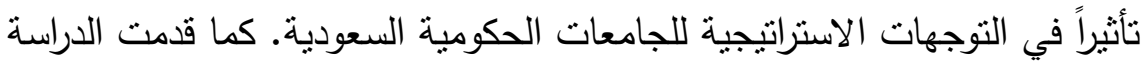
العديد من التوصيات لتحسين وتطوير الأداء والمكانة لجامعة الملك فيصل التي تم أخذها كحالة دراسية لاختبار وتطبيق فروض البحث عليها، ومن ثم تعميم

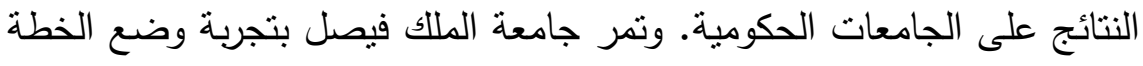

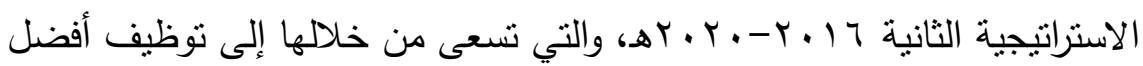
لكوادرها العلمية المتخصصة في لجان الخطة الرئيسة والفرعية بما يؤدى إلى نتائج تدعم مكانة ودور ورسالة الجامعة. تنقسم الاراسة إلى خمسة أقسام: أولاً: الإطار العام للاراسة ثانياً: الدراسات السابقة ثالثاً: بلورة نموذج مقترح لبناء التوجهات الاستراتيجية في الجامعات الحكومية السعودية رابعاً: تطبيق النموذج المقترح لبناء التوجهات الاستراتيجية في الجامعات الحكومية السعودية على جامعة الملك فيصل خامساً: توصيات الدراسة . 
ويتتاول مشكلة الدراسة، أهمية الدراسة، أهداف الدراسة، فروض الدراسة، منهجية الدراسة. 1 - مشكلة الدراسة:

تبحث الجامعات العربية عن موطئ قدم لها بين الجامعات العالمية الكبرى المتميزة التي حازت على سمعة وصيت عالمي، وضعها في مكان الصدارة لما تقدمه من خدمات تعليمية جيدة ونفع للمجتمع التي تخدمه، بل وللنفع العام الذي وهي

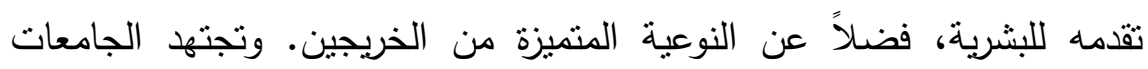
العربية في هذا السياق سعياً منها نحو التميز المحلي والدولي، خاصة أن أقدم الجامعات في العالم هي جامعات عربية.

وتجدر الإشارة إلى أن المساعي التي تقوم بها الجامعات العربية نحو هذا

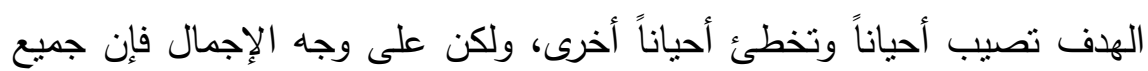
الجامعات العربية لم تصل احداها إلى أن يوضع اسمها بين المائة جامعة الأولى على مستوى العالم ، رغم عراقة العديد منها، ورغم أن العديد من كوادرها العلمية تتارك في صناعة تميز وتفوق العديد من الجامعات الأوروبية والأمريكية بعد رعدي هجرتها إليها للعمل فيها، ومن أهم المشكلات التي تمنع تطور وتقدم الجامعات العربية غياب التوجهات الاستراتيجية أمام أعين صناع القرار فيها ـ فبالرغم من إن وجود المكونات الأربعة المتمنلة في الرسالة والروئية والقيم والأهداف استراتيجية في معظم الجامعات العربية، إلا أن الواقع العملي يقول إن الأمور تسير عكس ماليال

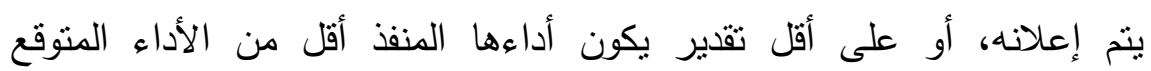
والمخطط له بكثير، خاصة مع تغير القيادات الجامعية، وتغير الأعضاء القائمين 
على وضع الخطة الاستراتيجية ومتابعتها، وغياب المعاييرالقياسية للرقابة عليها، وهو الأمر الذي يدفعنا للبحث عن طريقة للتغلب على هذه المشكلة الحقيقية المؤثرة على مستقبل الجامعات العربية بصفة عامة وعلى الجامعات السعودية الحكومية بصفة خاصة، وذلك بجعل التوجهات الاستراتيجية بمكوناتها الأربعة نصب أعين صناع القرار بشكل دائم يصعب تغييره، إلا في أضيق الحدود، فلا تتغير بتغير قيادات جامعية أو بأعضاء لجان معينة وإنما يسمح بالتغيير فقط تحت وطأة الظروف القهرية. تسعى هذه الدراسة إلى بناء نموذج للتوجهات الاستراتيجية من خلال مجموعة من المؤشرات تضبط إيقاع أدائها ، بما يخدم كافة الجهات المعنية وذات الصلة بالجامعة.

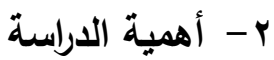
تستمد الدراسة أهميتها من ندرة الدراسات العربية والأجنبية التي تعرضت

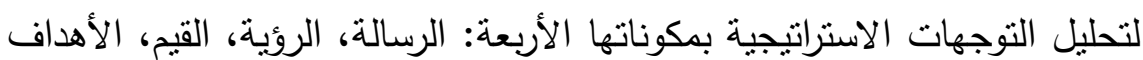
الاستراتيجية للمنظمات بشكل عام وللمؤسسات التعليمية بشكل خاص، كما أن فكرة النمذجة للتوجهات الاستراتيجية بمكوناتها الأربعة هي فكرة لم يجد الباحث من تتاولها في الدراسات السابقة من قبل سواء كانت عربية أو أجنبية. وتزيد من أهمية الدراسة أهمية ضبط التوجهات الاستراتيجية الطموحة وتوجيه كافة الطاقات والإمكانات نحو تحقيقها في المؤسسات التعليمية، وفي القلب منها الجامعات، والتي يعتبر منتجها من العنصر البشري أهم ما تقدمه للمجتمع، فضلاًا عما تقدمه الجامعات من خدمات للمجتمعات المتواجدة فيها في كل المجالات العلمية والبيئية والتعليمية. كما أن الدراسة تفكك مشكلة متجذرة في العالم العربي وهي ارتباط التوجهات الاستراتيجية للمؤسسة التعليمية بالقيادات الموجودة فيها. 
فإن تغيرت القيادات تغيرت التوجهات الاستراتيجية ، الأمر الذي يفقد المؤسسة التعليمية تراكم الخبرات عبر الزمن.

$$
\text { r- ب أهداف الدراسة }
$$

تعمل هذه الدراسة على تحقيق الأهداف التالية:

ا. دراسة امكانية استخدام النمذجة في تحديد التوجهات الاستراتيجية بالجامعات

$$
\text { الحكومية السعودية. }
$$

r. دراسة أثر التغيرات على التوجهات الاستراتيجية بالجامعات الحكومية الناتجة

$$
\text { عن التغير في التوجهات الاستراتيجية في: }
$$

أ. التوجهات الاستراتيجية للمملكة العربية السعودية

$$
\text { ب.التوجهات الاستراتيجية لوزارة التعليم العالي }
$$

ت .التوجهات الاستراتيجية للإقليم التي تعمل فيه الجامعة

$$
\text { ث.التوجهات الاستراتيجية للتميز بالجامعات العالمية }
$$

ج. التوجهات الاستراتيجية العالمية في التعليم العالي r. اقتراح نموذج لبناء التوجهات الاستراتيجية في الجامعات الحكومية السعودية.

$$
\text { ع - فروض الدراسة }
$$

بناء على منطقية التسلسل السابق المشار إليه في بناء التوجهات الاستراتيجية، وكما هو مستقر في أدبيات الإدارة الاستراتيجية ، يمكن صياغة فروض الدراسة (النموذج المقترح) محل البحث كما يلي: الفرض الأول: توجد علاقة ذات دلالة إحصائية بين التوجهات الاستراتيجية للمملكة ، والتوجهات الاستراتيجية للجامعات الحكومية من خلال الفروض الفرعية 
1-1 تؤثر التوجهات السياسية للدولة على التوجهات الاستراتيجية للجامعات الحكومية.

ا r-r تؤثر التوجهات الاقتصادية والمالية على التوجهات الاستراتيجية للجامعات الحكومية. ا ب تؤثر التوجهات الاجتماعية والثقافية على التوجهات الاستراتيجية للجامعات الحكومية. الفرض الثاني: توجد علاقة ذات دلالة إحصائية بين التوجهات الاستراتيجية لوزارة

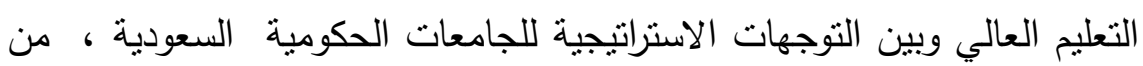
خلال الفروض الفرعية التالية: ץ-1 تؤثز مؤشرات أعضاء هيئة التدريس بوزارة التعليم العالي على التوجهات الاستراتيجية للجامعات الحكومية. r-r تؤثر مؤشرات الكفاءة والبحث العلمي بوزارة التعليم العالي على التوجهات الاستراتيجية للجامعات الحكومية. r-r تؤثز التوجهات الرسمية المعتمدة بوزارة التعليم العالي على التوجهات الاستراتيجية للجامعات الحكومية. الفرض الثالث: توجد علاقة ذات دلالة إحصائية بين التوجهات الاستراتيجية للإقليم المقام فيه الجامعة، وبين التوجهات الاستراتيجية للجامعات الحكومية السعودية، من خلال الفروض الفرعية التالية: r-1 يؤثر عدد سكان الإقليم على التوجهات الاستراتيجية للجامعات الحكومية. r-r تؤثز تقديرات السكان لسنوات الخطة الاستراتيجية على التوجهات الاستراتيجية للجامعات الحكومية السعودية. 
r-r تؤثر الحركة الاقتصادية بالإقليم على التوجهات الاستراتيجية للجامعات

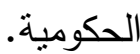

الفرض الرابع: توجد علاقة ذات دلالة إحصائية بين التوجهات الاستراتيجية

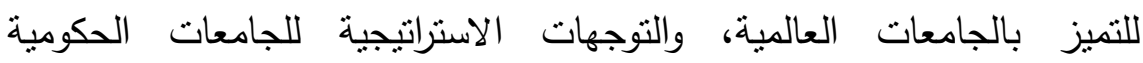
السعودية، من خلال الفروض الفرعية التالية:

ع- أؤثر عراقة وقدم الجامعة على التوجهات الاستراتيجية للجامعات الحكومية

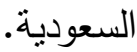

ع-r تؤثر البيئة والثقافة المحيطة بالجامعة على التوجهات الاستراتيجية للجامعات الحكومية السعودية.

ع-ب تؤثر معايير التصنيف العالمي للجامعات على التوجهات الاستراتيجية

للجامعات الحكومية السعودية.

الفرض الخامس: توجد علاقة ذات دلالة إحصائية بين التوجهات الاستراتيجية

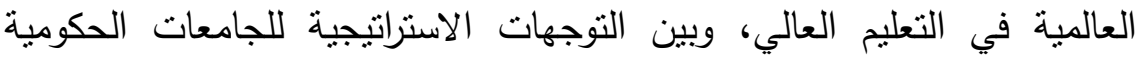
السعودية، من خلال الفروض الفرعية التالية:

0- تؤثز مؤشرات الطلاب المقيدين المقارنة على التوجهات الاستراتيجية

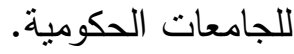

ت بؤثر مؤشرات الحراك الدولي المقارن على التوجهات الاستراتيجية للجامعات الحكومية.

0-T. تؤثر مؤشرات الكفاءة والبحث العلمي على التوجهات الاستراتيجية لامعات الحكومي-ة. ه- منهجية الدراسة: تتطلق منهجية الدراسة من محورين: الأول: استخدام المنهج الاستقرائي في إتمام الجانب النظري للارراسة، عند بناء نموذج التوجهات الاستراتيجية للجامعات الحكومية السعودية. 
الثاني: استخدام المنهج الاستتباطي في الجانب الميداني، واختبار الفروض الرئيسة، التي بُني عليها النموذج على جامعة الملك فيصل، باعتبارها أحد الجامعات الحكومية، ثم تطبيق النموذج المقترح كحالة دراسية على خطة جامعة

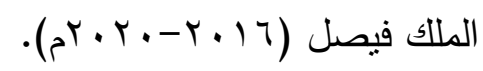
يلي ذللك ترتيب الإجراءات والعمل الميداني، بالبدء في بناء النموذج، واستكماله نظرياً، وصياغته في شكل استبيان، تم طرحه على العينة المستهدفة، وجمع البيانات ، ثم تحليلها باستخدام البرنامج الإحصائي SPSS، ثم استخلاص النتائج والتوصيات. ثانيا: الدراسات السابقة: نعرض فيما يلى لبعض الدراسات الأجنبية والعربية التي تقدم خبرات وتجارب متتوعة ، يمكن الاستفادة من نتائجها في تطوير مخرجات هذه الدراسة.

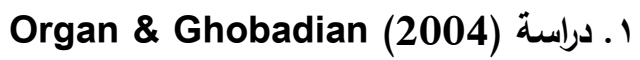

طرحت الدراسة السؤال المتكرر وهو لماذا يكون أداء بعض الثركات أفضل من الآخرى؟ وقامت بدراسة هذا الأمر من منظور التوجهات الاستراتيجية القائمة على قدرات المنظمة التنظيمية، ومدى تأثيرها على الأداء، والميزة التنافسية، ووضعت في ذلك افتراضين تم اختبارهما، الأول هو أن القدرات التتظيمية تساهم

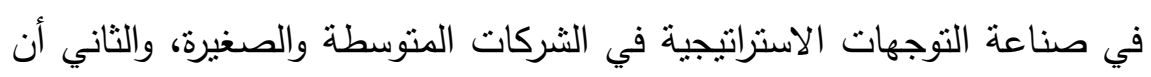
القدرات التنظيمية تؤئز على أداء الثركات المتوسطة والصغيرة. صممت الدراسة لاختبار فروضها سلسلة من المقابلات مع الرؤساء التتفيذيين للشركات المتوسطة والصغيرة، لفه العلاقة بين التوجهات الاستراتيجية والقدرات والكفاءات بهذه الثركات، وكذلك مقابلة بعض الموظفين تمثيلاً لفئة الموظفين في هذه الثركات. اختارت الدراسة قطاعين فقط من الصناعة في المملكة المتحدة rr 
لتجري عليها الدراسة، بناءً على ثلاثة شروط هي الأهمية الاقتصادية للقطاع، ومدى توفر عدد كافي من الشركات المتوسطة والصغيرة فيه، وأن منتجاتها مؤثرة في السوق وفي مرحلة النضوج، وبحسب هذه الشروط تم اختيار قطاعي الالكترونيات والهندسة. واستهدفت الدراسة عينة مكونة من . .. . شركة متوسطة وصغيرة، وكانت نسبة الاستجابة والتعاون \%rV\% بعدد ع 9 ا شركة. وقد انتهت الدراسة إلى أن: - القدرات التظيمية تمكن الشركات المتوسطة والصغيرة من ضبط توجهاتها الاستراتيجية في إدارة مستقبلها ،من خلال التركيز على احتياجات المستهلك ومتطلباته، وفي نفس الوقت تمكنها من إدارة أزماتها ومشاكلها في بيئتها

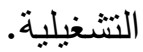
- القدرات التظظيمية في الثركات ذات الأداء العالي، أعلى بكثير من الثركات ذات الأداء المنخفض، مما يعني أن القدرات التنظيمية من العوامل الرئيسية التي

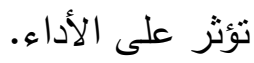
- الثركات التي تبحث عن الأداء العالي عليها أن تهتم بالأنشطة التي تولد قدرات إضافية ، ومن ثم تبني توجهات استراتيجية جديدة بناء على ذللك.

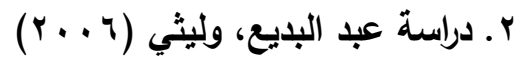
ناقتث الدراسة أهمية استخدام مدخل نمذجة الأعمال من منظور استراتيجي في تفعيل القياس المتوازن للأداء في منظمات الأعمال غير الخدمية (مجموعة شركات الصناعات المعدنية التابعة للشركة القابضة للصناعات المعدنية المصرية وعددها ثمانية عشر شركة)، حيث قامت الدراسة بمحاولة وضع إطار مقترح بربط 
بين مقومات نطبيق منهج التقويم المتوازن للأداء ومنطلبات النطبيق الناجح لاستراتيجية التوجه نحو العميل معتمداً في ذلك على مدخل نمذجة الأعمال. استخدمت الدراسة المنهج الاستقرائي في تحليل نتائج الدراسات السابقة المرتبطة بموضوع البحث، بهدف استخلاص أهم المقومات التي يمكن أن يبنى عليها الإطار المتكامل الذي يربط بين منهج التقويم المتوازن للأداء ، ومتطلبات تطبيق استراتيجية التوجه نحو العميل. وطبقت الدراسة ميدانياً باستخدام مدخل النمذجة القائم على أساس صباغة علاقات السبب والنتيجة المبنية على قاعدة إذا-إذاً (If-Then) في وضع إطار مقترح يحقق التكامل بين مقومات التقويم المتوازن للأداء، ومتطلبات تطبيق استراتيجية التوجه نحو العميل في تللك المنظمات.

\section{وكان من ضمن نتائج الدراسة:}

- إن بناء إطار متكامل لتقويم الأداء المتوازن يمكن تطبيقه في شركات قطاع الصناعات المعدنية، ويدعم استراتيجية التوجه نحو العمبل. - أن المراحل الرئيسة للإطار المقترح بخطواتها التفصيلية بحسب مدخل النمذجة، هي مراحل وخطوات ذات علاقة منبادلة ومتكاملة مبنية على قاعدة

$$
\text { السبب/النتيجة (إذا -إذاً). }
$$

- صياغة مؤشرات للتقيم المتوازن للأداء الاستراتيجي بشركات قطاع الصناعات المعدنية طبقاً للإطار المقترح. 
Quartel, Jonkers \& Sinderen (2011) ب-دراسة

استهدفت الدراسة تقديم لغة لنمذجة الدوافع لدى أصحاب المصلحة لهيكلة الثركات ، من خلال أهدافها واحتياجاتها المختلفة وأسمتها (ARMOR) ، وذلك من خلال صيغة منوافقة مع لغة (ArchiMate) وهي لغة تستخدم لوصف وبناء وتتغيل العمليات التجارية، والهياكل التظظيمية، وتدفق المعلومات وأنظمة تقنية المعلومات، والبنية التحتية للتقنية، وتساعد أصحاب المصلحة في الثركات، لتصميم وثقيم القرارات ، ومعرفة آثارها المختلفة ، سواء في داخل الثركة أو

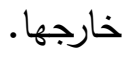
اعتمدت الدراسة في تأسيس لغة (ARMOR) لهيكلة الثركات من منظور تقنية المعلومات حسب المنهجية التالية: - مناقتنة إطار نمذجة لغة (ArchiMate) وصلتها بنمذجة الدوافع. - مناقثة العلاقة بين إعادة هندسة الشركة وهيكلتها. - تحليل اللغة المعمول بها في نمذجة الاحتباجات وتكوين الأفكار والاحتباجات للغة المقترحة (ARMOR). - صياغة مصطلحات ومفاهيم اللغة المقترحة (ARMOR) ، وما يتعلق بها في النشأة والتكوين. - أخيراً إسقاط اللغة المقترحة على (ARMOR) على مثال واقعي، وهو تسجيل المرضى في مراكز الرعاية الصحية، وتحليل التقنيات المختلفة في ذلك، وأدوات الاعم المتاحة للغة المقترحة. وانتهت الدراسة إلى تكوين اللغة الجديدة للنمذجة (ARMOR) ، والتي تتسق في مجملها مع لغة النمذجة للشركات القياسية (ArchiMate). وأهم ما يميز اللغة 
الجديدة أنها تتبع مخاوف أصحاب المصلحة ، من خلال نتبع أهدافهم التي يبحثون عنها في نموذج هيكلة الثركة القصيرة وطويلة الأجل، كما يطرح النموذج بدائلا يمكن لأصحاب المصلحة، اختيار الأكثر ملائمة لهم من بينها. عiu, Eng \& Ko (2012) ك-دراسة

هدفت الدراسة تقديم نموذج جديد للمشاركة المجتمعية للشركات ، يعتمد على

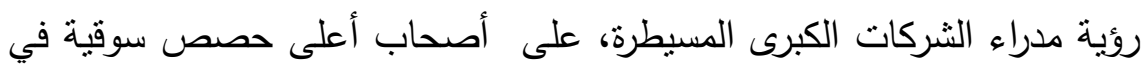
أنشطتها ، لما يسمى باهتمامات أصحاب المصلحة المجتمعية، ودراسة دوافع هذه الثركات في إدارة أصحاب المصلحة المرتبطين بها. تم تصميم الدراسة للوصول إلى هدفها على ثلاث مراحل:

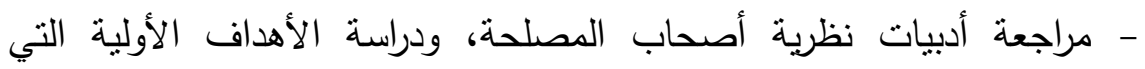
يضعها أصحاب المصلحة للمشاركة المجتمعية للشركات من وجهة نظرهم، ثم الثمابه التحليل الوصفي لأهدافهم وأولوياتها ، آليات التعامل معها، والأدوات التي يتم

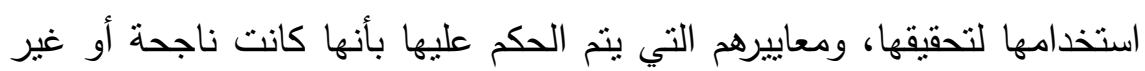
ذلك.

- مراجعة أدبيات رأس المال المجتمي، ومناقشة كيف يتم تكوين الأبعاد

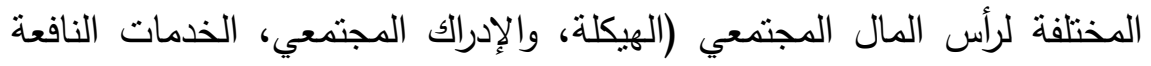

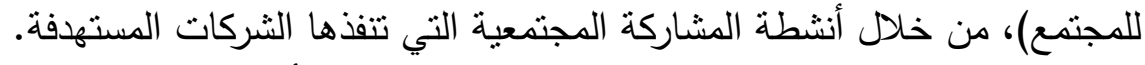

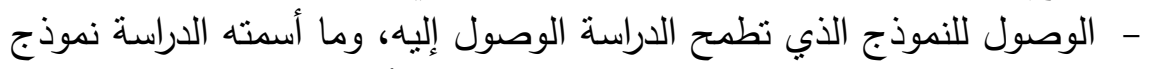

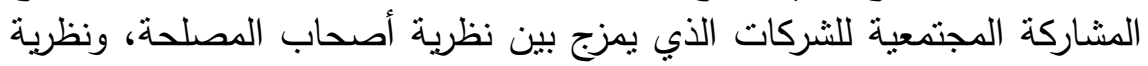
رأس المال المجتمعي. وانتهت الدراسة إلى تقديم وجهة نظر لفهم المخرجات المتوقعة لما يتمنى مدراء الثركات إنجازه، نتيجة لاستثمارهم في المشاركات المجتمعية، وتقديم نموذج 
للمشاركة المجتمعية في تحقيق توجهات المجتمع الاستراتيجية، والتي حددتها الدراسة في تسعة توجهات هي:

- ثلاثة داخل المنظمة تقوم على هيكلة الثركة وهي: الوعي التنظيمي، القبول التتظيمي، المساعلة التتظيمية. - ثلاثة تقوم على البعد الإدراكي للمجتمع المحيط بالثركات وهي: شبكات الوصول، شبكات التعاون، شبكة الولاءات. - ثناثة تقوم على العلاقات بين أفراد المجتمع وهي: التقاعل المجتمعي، والوئام المجتمعي، التماسك المجتمعي.

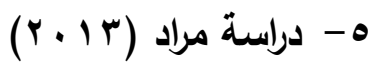

تتتاول هذه الدراسة إثكالية الانفتاح الاقتصادي في الجمهورية الجزائرية كأحد الرهانات الرئيسة للتتمية فيها، حيث تبحث في التعرف على أهم العوامل التي تحدد المتغيرات الكلية للاقتصاد التي تعول عليها الدولة كثيرا في دفع عجلة النمو والانفتاح الاقتصادي، وتهدف الدراسة إلى توفير قاعدة معلومات إضافية لمستخدمي البيانات الاقتصادية للهياكل الرئيسة التي تتحكم في سياسات الانفتاح الاقتصادي، والمساعدة في تقدير الخطر الناتج عن سياسات الانفتاح الاقتصادي، والوقوف على معايير النجاح في الاقتصاد الجزائري، وتحديد مؤشرات قابلة للقياس ومقارنتها بمعايير الاقتصادات الأخرى. اعتمدت الدراسة في البداية على استتباط نموذج قياسي كلي خاص بالاقتصاد الجزائري للتتبؤ بمتغيراته على المدى القصبر والمتوسط والطويل، المتغير التابع فيه هو الناتج الحلي الإجمالي والمتغيرات المسنقلة هي الانفتاح المالي، الاستثمار الإجمالي، صافي التجارة الخارجية، وحجم الاستهلاك النهائي. ثم تم استكمال 
الدراسة من خلال المنهج الوصفي التحليلي، وباستخدام نموذج إحصائي هو تحليل الانحدار المتعدد عبر سلسلة زمنية محددة.

انتهت الدراسة إلى اسنتباط نموذج قياسي كلي خاص بحالة الاقتصاد الجزائري، يمكن من خلاله التتبؤ بمتغيراته على المدى القصير والمتوسط والطويل، واستتناج أهم المتغيرات القيادية المؤثرة في الاقتصاد الكلي الجزائري والتي أمكن من خلالها دراسة الصدمات التي يمر بها الاقتصاد، وأهم السياسات الواجب إتباعها مستقبلاً، وأخيرا قدمت الدراسة العديد من المقترحات التحسينية لأداء السياسات الاقتصادية الجزائرية في المستقبل أهمها: - بالنسبة للسياسات المالية: قدمت أربعة مقترحات تحسينية. - بالنسبة للسياسات النقدية: قدمت أربعة مقترحات تحسينية. - كما اقترحت الدراسة إنشاء تكامل عربي موحد.

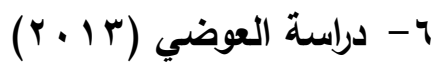

تتتاول الدراسة إثكالية إنشاء فروع للجامعات بالخارج، وما يتبعه من مجازفات، تتعلق بفنّل الفرع في تحقيق أهدافه، وبالتالي ما يحدثه من آثار سلبية

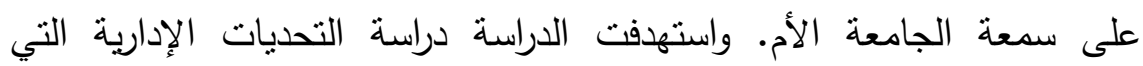
تواجهها الفروع، وبشكل خاص تحدي إدارة الموارد البشرية من خلال التساؤلات

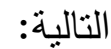
- ما هو التوجه المستقبلي لإدارة الموارد البشرية في فروع الجامعات العالمية في دولة الإمارات؟ مأمو - ما هي ألبة تطوير إدارة الموارد البشرية في فروع الجامعات العالمية في دولة

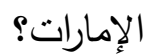


- ما هو موقع نظام إدارة الموارد البشرية في فروع الجامعات العالمية في دولة الإمارات قياساً بأنظمة الموارد البشرية العاملة في الدولة ؟ وما أبرز المعوقات

$$
\text { التي تواجهها؟ }
$$

وقد استخدمت الدراسة طرق البحث النوعي لجمع وتتظيم وتحليل البيانات

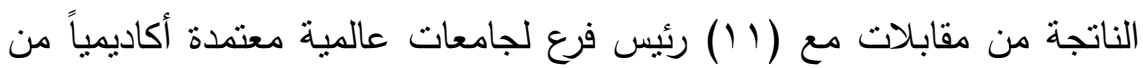

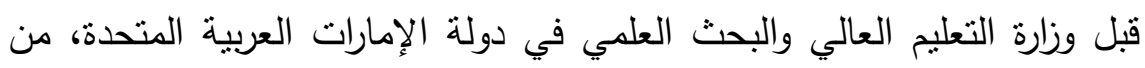
مجتمع دراسة قدرة (0؛) فرع داخل الدولة، إلا أن الأحد عشر جامعة المنتقاة في العينة هي المعتمدة أكاديمياً من الوزارة. واشتملت أداة المقابلة على ثلاثة أسئلة توجه إلى رئيس فرع الجامعة العالمية، تغطي مستهدفات الدراسة التي طمحت

\section{وإنتهت الدراسة إلى النتائج التالية:}

- أن إدارة الموارد البشرية في فروع الجامعات العالمية ، تتبع نظام إدارة مركزي مختلط بمعايير عالمية ، أبرزها في التوظيف والاستقطاب وأعداد طلبة ومدرسين ونسب طلاب إلى أعضاء هيئة التدريس. - أن إدارة الموارد البشرية في فروع الجامعات العالمية في الإمارات ذات نظام

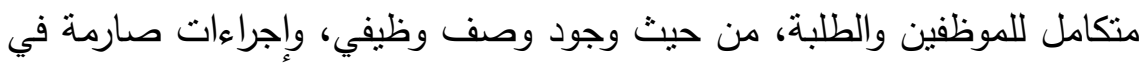
التعيين والتدريب. - أن موقع نظام إدارة الموارد البشرية في فروع الجامعات العالمية في الإمارات، ينراوح ما بين الانغلاق على الذات، والتكيف محلياً مع أنظمة الدولة الداخلية.

Francis\& Mathooko (2015) دراسة

تبحث الدراسة إثكالية التحديات التي تواجهها الجامعات الحكومية في كينيا،

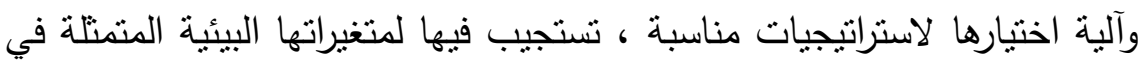


الفرص المتاحة والتهديدات التي تتعرض لها من أجل تحقيق ميزة تتافسية مستدامة ، تخفف من خلالها المخاطر التي تتعرض لها وتهن ونمكنها من تحسين الأداء واقتتاص الفرص المتاحة.

واستخدمت الدراسة نموذج بورتز للقوى التتافسية الخمسة (المنافسين الجدد، التهاء

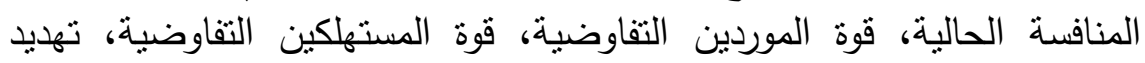
البدائل) ، على اعتبار أن المستهلك والمورد هو المجتمع، كإطار سعى من خلاله

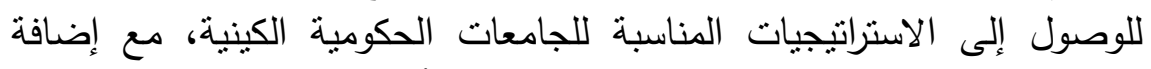

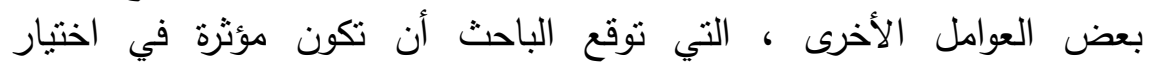

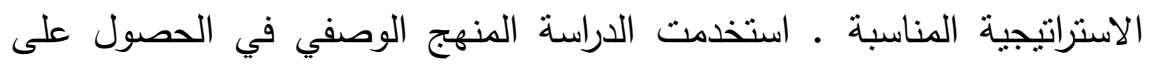

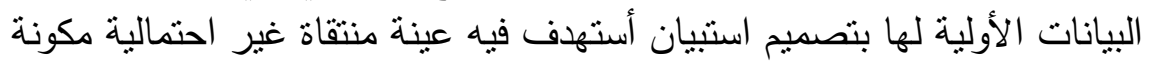

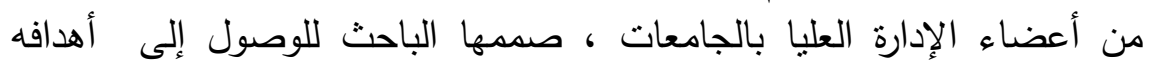

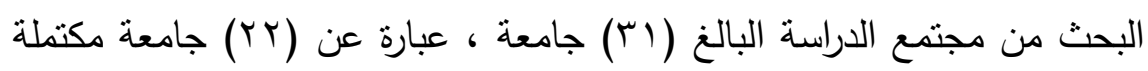

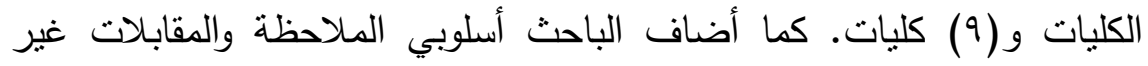

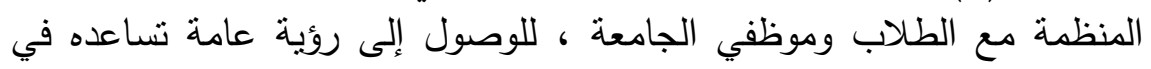
إنجاز الدراسة.

\section{وانتهت الدراسة إلى العديد من النتائج أهمها:}

- أن الجامعات تطبق الاستراتيجيات التقليدية المحفوظة لديها والمجربة عدة الداء

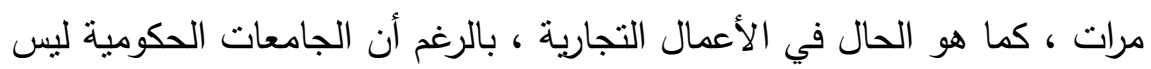
بالضرورة أن تهدف في استراتيجياتها إلى الربح.

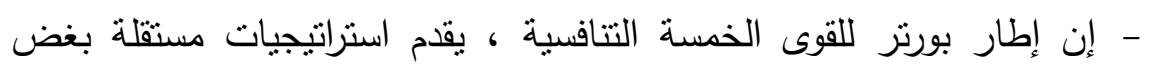

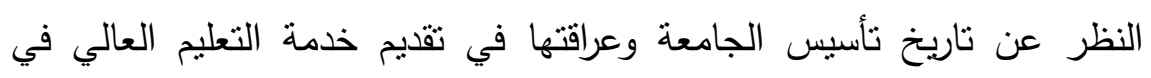
كينيا.

- أظهرت الدراسة دور الحكومة البارز في اختيار الاستراتيجيات المستقبلية للجامعات الحكومية ، خاصة تلك التي تتعلق بالمتغيرات البيئية التي قد تملي على الحكومة أتخاذ قرارات تمليها على الجامعات الحكومية. 
ونخلص من الدراسات السابقة إلى أهم النتائج التالية:

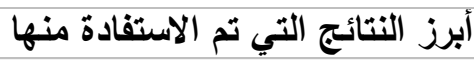
الاراسة

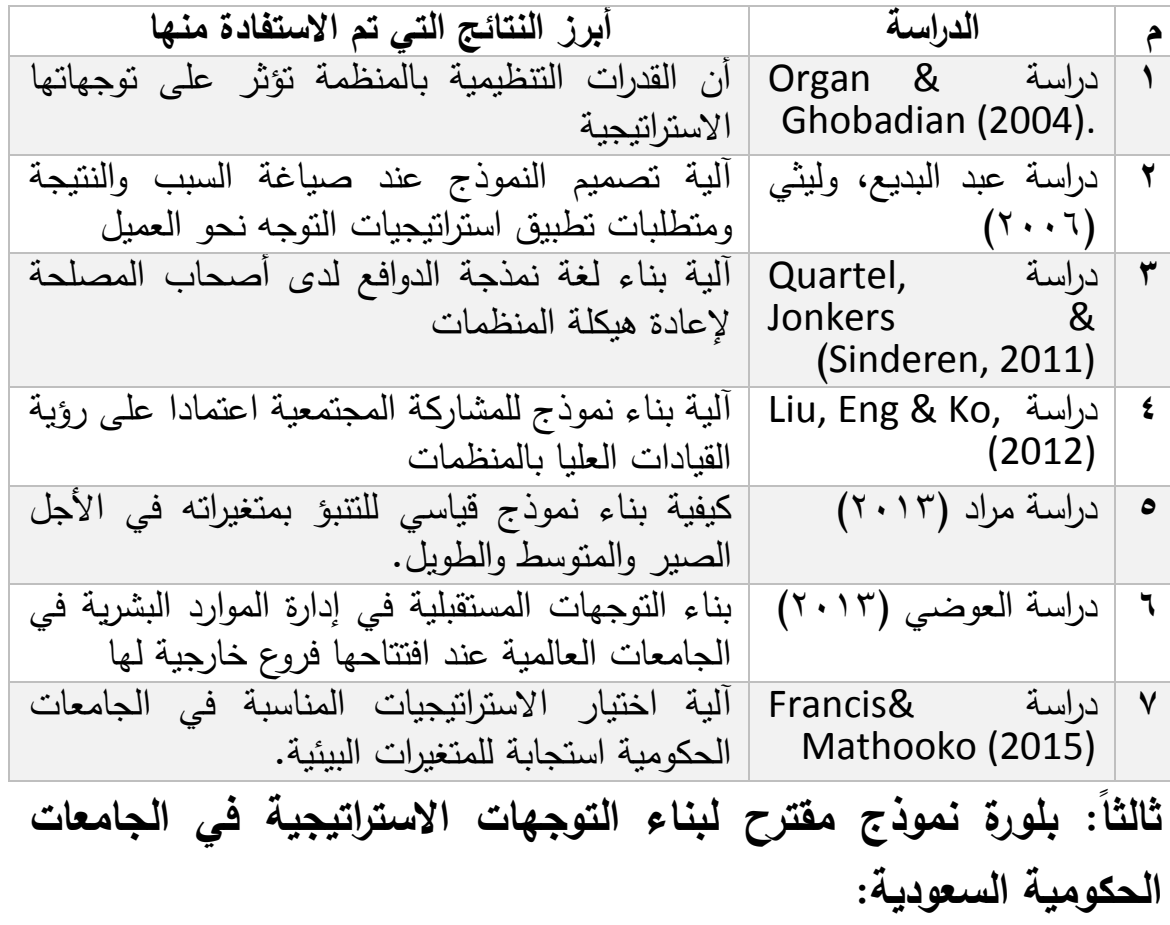

تمثل عملية تحديد الاتجاه الاستراتيجي في أب منظمة المهمة الأصعب للإدارة

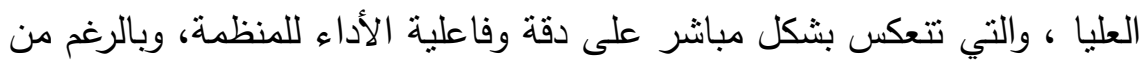

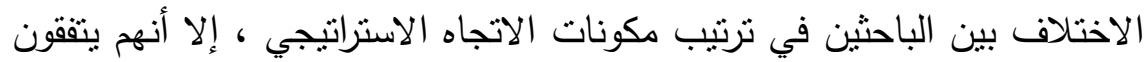

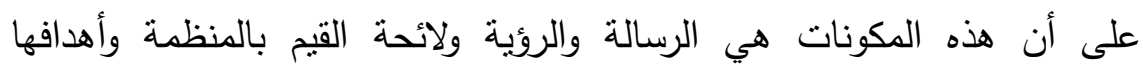
الاستراتيجية، وقد أثنار بعض الباحثان (Certo \& peter,1995) إلى أن الاتجاه الاستراتيجي، يبدأ أولاً بتحديد الرؤية المستقبلية، ثم تحدد الرسالة في إطار هذانه

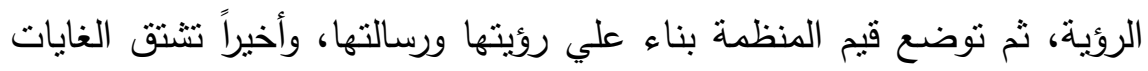
والأهداف الاستراتيجية. في حين يشير أغلب الباحثون (Irland\&Hill,1992)،

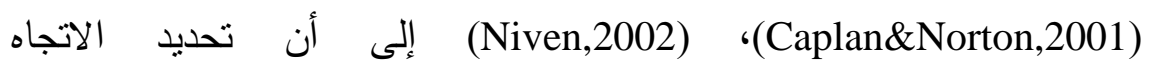


الاستراتيجي، يبدأ بتحديد الرسالة، ثم تحدد القيم في إطار هذه الرسالة ثم تحدد روية المنظمة، وأخيراً تشتق الغايات والأهداف الاستراتيجية. وتعتبر هذه الدراسة الدانة أن الرأي الأخير هو الأقرب للاقة، وبالتالي اعتمدته كمنهجية لها.

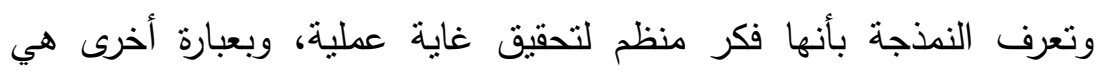

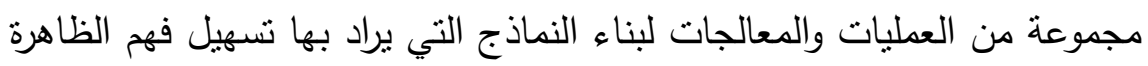

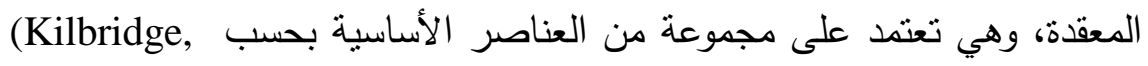
(1961 تشنمل على: موضوع النموذج، والمهمة التي سيؤديها، والنظرية التي يستتد عليها، والطريقة التي يستخدم النموذج بها نظريته. وبناء على مبدأ وحدة التوجه الاستراتيجي الذي يقوم على حتمية اتباع المستوى الإداري الأدنى توجهات

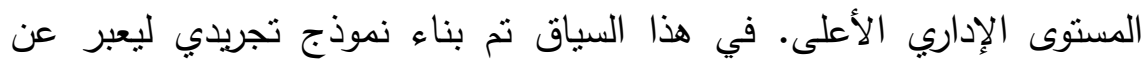

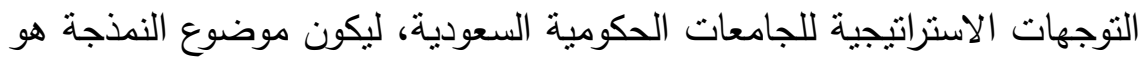
التوجهات الاستراتيجية في الجامعات الحكومية السعودية، ومهمته التتبؤ بالتوجهات المستقبلية، ونظريته هو وحدة التوجهات الاستراتيجية بالجامعات

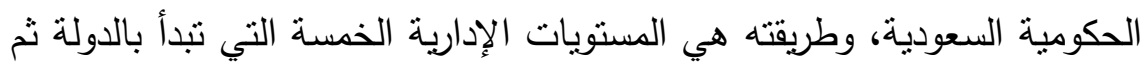

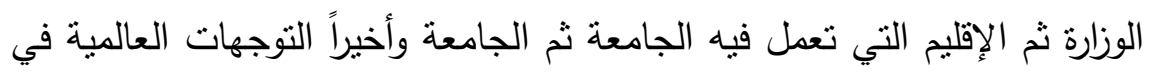
وتجدر الإثارة إلى ارتباط أمر تحديد الغايات والأهداف في المنظمات بأمرين التعليم العالي.

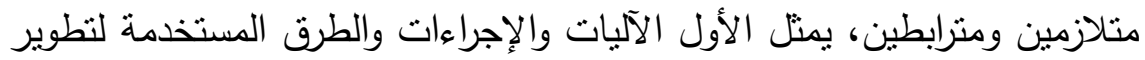

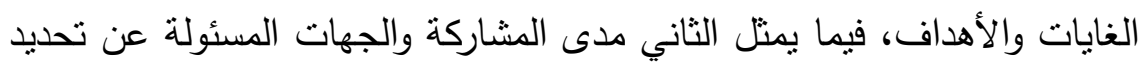

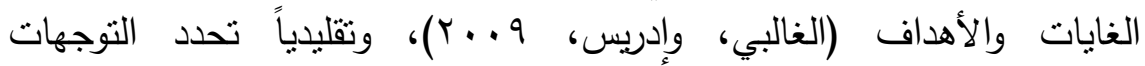

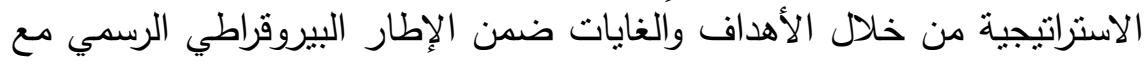

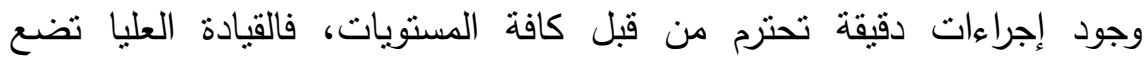

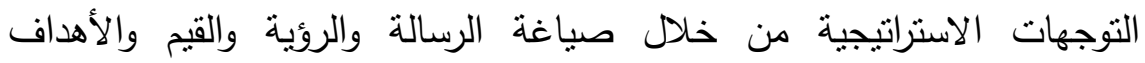

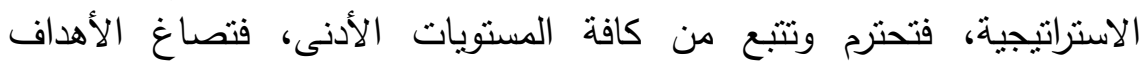

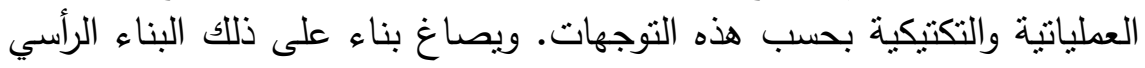
للنموذج كما يتضح بالثكل رقم (1) التالي: 


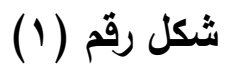

مستويات التوجهات المرتبطة بعملية التخطيط الاستراتيجي في الجامعات السعودية له
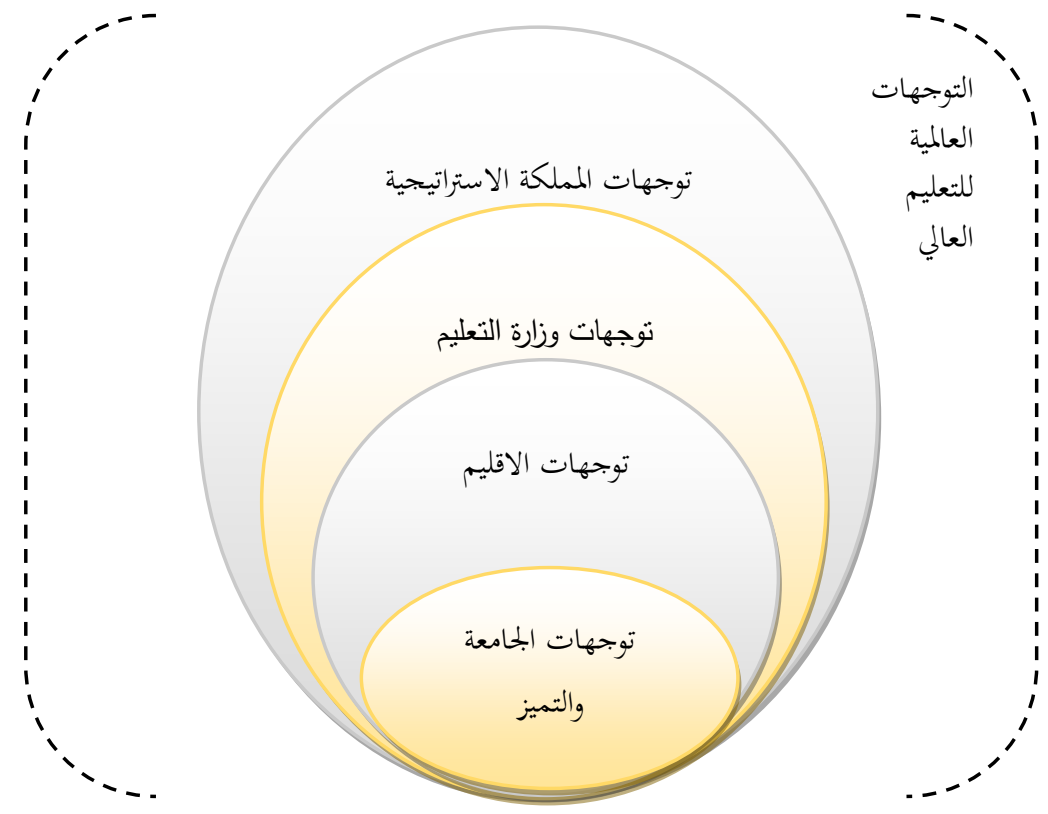

المصدر: من إعداد الباحث.

أما المحور الأفقي الذي يتمثل في المؤثرات التي سيعتمد عليها النموذج في تحديد التوجهات الاستراتيجية للجامعات الحكومية وهي المؤشرات العالمية التي تعتمدها منظمة الأمم المتحدة، والمتمتلة في مؤشرات التعليم العالي التي يرصدها معهد اليونيسكو للإحصاء من خلال بيانات (القيد والخريجين والمدرسين والإنفاق 
والتحصيل التعليمي والأمية والقرائية) وكل بند من هذه البنود له تفاصيل كثيرة وطرق رياضية لحسابها (/http://www.unesco.org). بناء على ما سبق قام الباحث باشتقاق النموذج المقترح الموضح في الثكل رقم (Y) (Y)، وهو يحتوي على (r)

\section{1-توجهات المملكة الاستراتيجية: من خلال حزم المؤشرات الآتية:} - التوجهات السياسية: (الاستراتيجية الوطنية للتحول إلى مجتمع المعرفة، نمو عدد الجامعات، نمو عدد الجامعات لكل مليون نسمة، نمو عدد الكليات، نوزيع الجامعات حسب المناطق الإدارية، ومدى تتاسب عددها مع عدد السكان).

- التوجهات الاقتصادية والمالية (الاستراتيجية بعيدة المدى Or •rم، تتوع البرامج والتخصصات، نمو الإنفاق على التعليم الحكومي، نسبة الإنفاق الحكومي على التعليم العالي من إجمالي الإنفاق الحكومي، معدل الإنفاق الحكومي على الطالب في مؤسسات التعليم العالي، معدل الإنفاق الحكومي على الطالب كنسبة من نصيب الفرد من الناتج المحلي الإجمالي، الإنفاق الحكومي على التعليم العالي كنسبة من الناتج المحلي الإجمالي ومقارنته عالمياُ، الإنفاق الحكومي على لإنى الطالب في التعليم العالي كنسبة من نصيب الفرد من الناتج المحلي الإجمالي

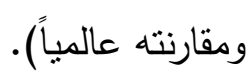


شكل رقم (ץ) النموذج المقترح لهيكلة وارتباطات التوجهات الاستراتيجية

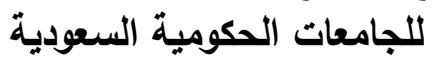

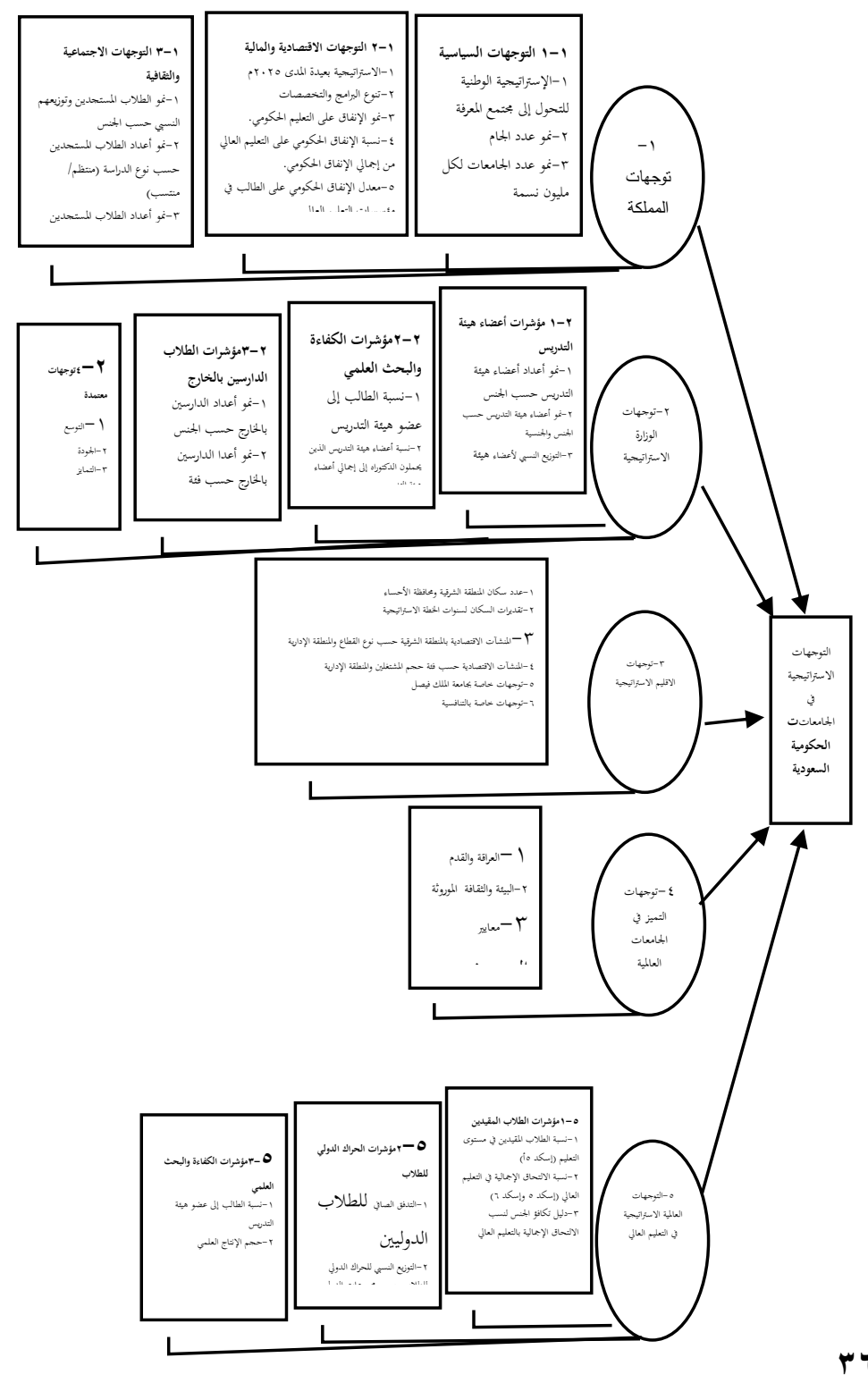


- التوجهات الاجتماعية والثقافية (نمو الطلاب المستجدين وتوزيعهم النسبي حسب الجنس، نمو أعداد الطلاب المستجدين حسب نوع الدراسة (منتظم/ منتسب)، نمو أعداد الطلاب المستجدين حسب جهة الدراسة (حكومي/ أهلي)، نمو أعداد الطلاب المستجدين حسب الجنسية، التوزيع النسبي للطلاب الطبه المستجدين حسب المستوى التعليمي) - توجهات الوزارة الاستراتيجية من خلال حزم المؤشرات الآتية: • مؤشرات أعضاء هيئة التدريس (نمو أعداد أعضاء هيئة التدريس حسبه الجنس، نمو أعضاء هيئة التدريس حسب الجنس والجنسية، التوزيع النسبي لأعضاء هيئة التدريس حسب الجنسية، التوزيع النسبي لأعضاء هيئة التدريس هينة حسب المناطق الإدارية، التوزيع النسبي لأعضاء هيئة التدريس حسب المستوى

التعليمي، دليل التكافؤ). • مؤشرات الكفاءة والبحث العلمي (نسبة الطالب إلى عضو هيئة التدريس، نسبة أعضاء هيئة التدريس الذين يحملون الدكتوراه إلى إجمالي أعضاء هيئة التدريس، نسبة الطالب للذين يحملون درجة الدكتوراه، نمو الطلاب في مرحلتي الماجستير والدكتوراه، نمو الإنتاج البحثي حسب قاعدة ISI/ SCOPUS • مؤشرات الطلاب الدارسين بالخارج (نمو أعداد الدارسين بالخارج حسب الجنس، نمو أعدا الدارسين بالخارج حسب فئة الابتعاث، نمو أعداد الدارسين بالخارج حسب مستوى التعليم التوزيع النسبي للطلاب الدارسين في الخارج حسب مجال التعليم، دليل نكافؤ الجنس لطلاب الخارج • توجهات معتمدة (التوسع، الجودة، التمايز) - توجهات الإقليم الاستراتيجية من خلال حزمة المؤشرات الأتية: rv 
• (عدد سكان المنطقة الثرقية ومحافظة الأحساء، تقديرات السكان لسنوات الخطة الاستراتيجية، المنشآت الاقتصادية بالمنطقة الشرقية حسب نوع القطاع والمنطقة الإدارية، المنشآت الاقتصادية حسب فئة حجم المشتغلين والمنطقة الإدارية، توجهات خاصة بجامعة الملك فيصل، توجهات خاصة بالتتافسية) - توجهات التميز الاستراتيجية بالجامعات العالمية من خلال حزمة المؤشرات الآتية:

• (العراقة والقدم، البيئة والثقافة الموروثة، معايير التصنيف العالمية) - التوجهات العالمية الاستراتيجية في التعليم العالي من خلال الحزم الأتية: • مؤثرات الطلاب المقيدين (نسبة الطلاب المقيدين في مستوى التعليم (إسكد هأ)، نسبة الالتحاق الإجمالية في التعليم العالي (إسكد ه وإسكد 7)، دليل تكافؤ الجنس لنسب الالتحاق الإجمالية بالتعليم العالي) • مؤشرات الحراك الدولي للطلاب (التدفق الصافي للطلاب الدوليين، التوزيع النسبي للحراك الدولي للطلاب حسب مجموعات الدول) • مؤشرات الكفاءة والبحث العلمي (نسبة الطالب إلى عضو هيئة التدريس، حجم الإنتاج العلمي)

رابعا: تطبيق النموذج المقترح لبناء التوجهات الاستراتيجية في الجامعات الحكومية السعودية على جامعة الملك فيصل تعتبر الجامعات الحكومية من أهم الركائز التي تبنى الدولة من خلالها مواردها البشرية، كما تعتبر المخزون الاستراتيجي وبيت الخبرة في كافة المجالات 
والتخصصات التي تحتاجها، وتعنتر جامعة الملك فيصل أحد أبرز وأقدم الجامعات بالمملكة العربية السعودية، لذلك كان التوجه لها لاختبار النموذج. وتمتلك المملكة العربية السعودية عب جامعة منها مب جامعة حكومية و 9

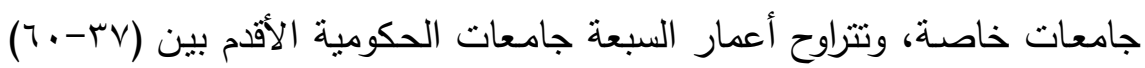
عاماً منذ تأسيسها، أما بقية الجامعات الحكومية فنتراوح أعمارها بين ( V-0) عام أي تعتبر حديثه التأسيس نسبياً إذا ما قورنت بالسبعة جامعات الأولى.

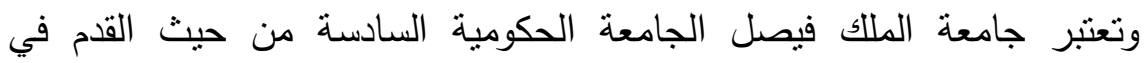
المملكة حيث تم تأسيسها عام 9 ام ام، كما تعتبر الجامعة الحكومية الأولى من حيث القدم في المنطقة الثرقية بالمملكة العربية السعودية. وقد خاضت جامعة الملك فيصل تجربة التخطيط الاستراتيجي مبكراً، إلا أن البداية الحقيقية وبشكل موثق ومعلن كان في عام • 1 • rم حيث أعلنت خطتها

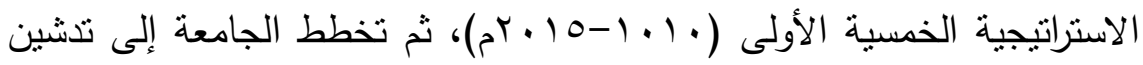

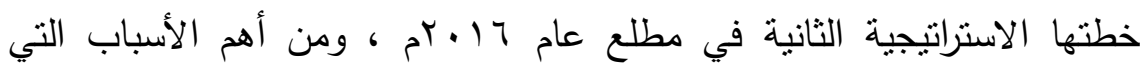
دعت لاختبار جامعة الملك فيصل كحالة تطبيقية لنموذج التوجهات الاستراتيجية المقترح للجامعات الحكومية بالمملكة العربية السعودية بالإضافة إلى أنها من أقدم الجامعات السعودية واحتوائها على كل الكليات التي تلبي حاجة المجتمع تقريباً، هو البدء في هذه الدراسة أثناء الإعداد لبناء الخطة الاستراتيجية الثانية (T ( • r-

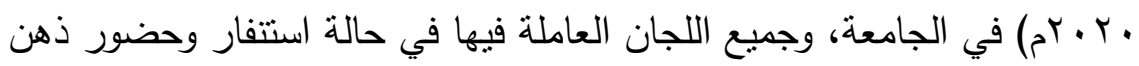
في كل ما يتعلق بالأمور العامة أو التفصيلية الخاصة بالخطة. وتحتوي جامعة الملك فيصل على 17 كلية، ب/ عمادة مساندة منها عمادة التعلم الإكتروني والتعلم عن بعد، ومعهد للبحوث والدراسات وسا امركز علمي وبحثي،

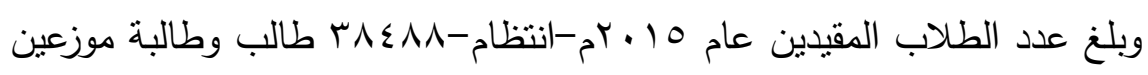


على كليات الجامعة، بينما بلغ عدد طلاب التعلم عن بعد س1/101اطالب وطالبة يدرسون من خلال نظام البلاك بورد. وتبلغ مساحة الجامعة في موقعها الرئيسي عمليون متر مربع ولديها مركز للتدريب والأبحاث الزراعية والبيطرية

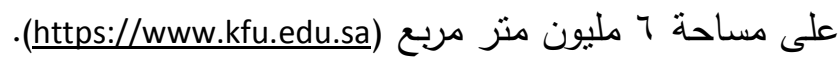
وقد اعتمدت الدراسة على عينة عمدية Purposive sample تتشكل من أعضاء مناء

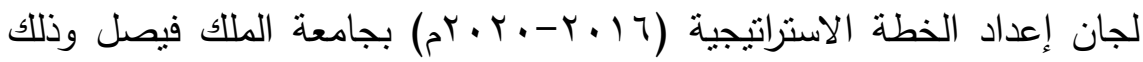

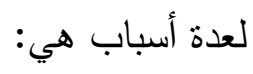
ا- أن جامعة الملك فيصل في طور إعداد الخطة وتوجه كل مواردها لإنجازها في الموعد المحدد r- أن أعضاء اللجان في وقت إعداد الدراسة يمارسون أعمال الخطة سواء بالاجتماعات أو الدراسات أو ورش أوش أعمل. r-أن أعضاء الخطة هم المعنيون بجمع وتتظيم وتلخيص كل البيانات المستخدمة في إعداد الخطة وتحديد توجهاتها المستقبلية. ع-أن أعضاء الخطة مجموعة منتقاة بعناية من الجامعة تتمثل فيها الخبرة في إعداد الخطط الاستراتيجية، وفي الشئون الأكاديمية، وخدمة المجتمع. وتعتبر هذه الأمور الأكثر أهمية في بناء التوجهات الاستراتيجية. وقد شكلت جامعة الملك فيصل هيكلاً هرمياً للخطة الاستراتيجية يتكون من: لجنة الاهنة رئيسية عددها · ا أعضاء برئاسة وكيل الجامعة للتطوير وخدمة المجتمع وعضوية وكيل الجامعة للبحث العلمي، عمداء الجودة، وكليات عملية ونظرية، ورؤساء إدارات، وبعض المتخصصين في التخطيط الاستراتيجي، و • 1 لجان فرعية بدءاً من تحليل البيئة الداخلية والبيئة الخارجية، وانتهاء بلجنة الصياغة. 
وقد بلغ أعضاء اللجان or عضواً، إلا أن بعض الأعضاء كان ممثلا في أكثر من لجنة ليصبح العدد الفعلي للعاملين في إعداد الخطة الاستراتيجية بس عضواً (7 أستاذ، 17 أستاذ مشارك، ع ا أستاذ مساعد)، وبذلك تصبح العينة المستهدفة דr عضواً. وقد تم توزيع النموذج الذي نم صياغته في شكل استبيان على العينة المستهذفة، وبلغ عدد الاستبيانات المستردة (Y9) وجميعها صحيحة، وتعذر الحصول على بقية الاستبيانات لأسباب متعددة جميعها لظروف شخصية تتعلق بأصحابها. وقد تم اختبار صدق وثبات العينة باستخدام معامل ألفا كورنباخ وكانت النتيجة مرضية جداً حيث بلغت قيمة المعامل 9V7 .97 . . كما تم استخدام اختبار (T) لاستتناج دلالة الفروق بين منتسط مجموعات المؤشرات المكونة للنموذج والوسط الفرضي (والبالغ قيمته ب بحسب مقياس ليكرت المستخدم في النموذج)، واستخدام معامل "T" ينص على أنه "لا توجد فروق دالة إحصائيًا بين متوسط العينة والمتوسط الفرضي في قبول المؤشرات المقترحة، لاستتناج التوجهات الاستراتيجية بمستوياتها الخمسة، وللتحقق من صحة هذا الفرض تم حساب قيمة "T" لقياس دلالة الفروق بين متوسط درجات كل مجموعة من المؤشرات المكونة للتوجه الاستراتيجي والمتوسط الفرضي للمستوبات الخمسة المقترحة بالنموذج.

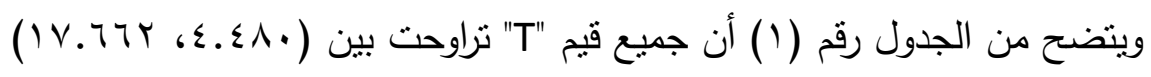
وهي قيم دالة إحصائياً عند مستوى معنوية (1 (...)، وهذا ما يشير إلى وجود 
فروق دالة إحصائياً بين متوسطات درجات العينة والمتوسط الفرضي في جميع مستويات النموذج والدرجة الكلية وذللك لصالح متوسط .

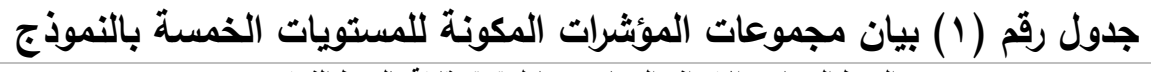

\begin{tabular}{|c|c|c|c|c|}
\hline \multicolumn{5}{|c|}{ الوسط الحسابي والانحراف المعياري ومعامل "ت" مقارنة بالوسط الفرضي } \\
\hline الفرضي عن الوسط & الانحراف المعياري & الوسط الحسابي & المكونات & التوجه العام \\
\hline $1 . .1 .9$ &. .74 & \$.19 & 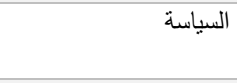 & مجموعة مؤثرات المملكة \\
\hline 9.51 &.. $\mathrm{Vr}$ & $\varepsilon .19$ & الاقتصادية والمالية & \\
\hline $\mathrm{V} .07 \mathrm{~V}$ & $. \vee \vee \leqslant$ & r.10 & الاجتماعية والثقافية & \\
\hline $\mathrm{V} .10 \mathrm{~V}$ &..$v \varepsilon$ & r.9V & أعضاء هيئة التدريس & مجموعة مؤشرات وزارة \\
\hline T.VA &. $.9 \mathrm{~V}$ & $\varepsilon . .0$ & الكفاءة والبحث العلمي & \\
\hline r.ros & $1 . . \mathrm{V}$ & T.T) & 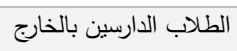 & \\
\hline IV.TTY & $.0 \mathrm{r}$ & ¿.74 & 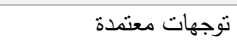 & \\
\hline V.r $Y \xi$ &. .11 & $\varepsilon . .9$ & & مجموعة مؤشرات المنطقة \\
\hline $1 . r \leqslant v$ &..$V T$ & $\varepsilon . r T$ & & في الجامعات مؤشرات التميز \\
\hline ¿.£A &.$\vee v \varepsilon$ & r.vi & الطلاب المقيدين & مجموعة $\quad$ المؤشرات \\
\hline r.007 & $1 . .9$ & r.or & الحراك الدولي للطلاب & \\
\hline T.t.T & $1 . . \varepsilon$ & V.IV & الكفاءة والبحث العلمي & \\
\hline
\end{tabular}

وقد تم استخدام سلاسل زمنية مختلفة حسب المتاح من قبل المؤسسات الرسمية المعنية بذلك في المملكة العربية السعودية، والتي ثراوحت بوجه عام بين

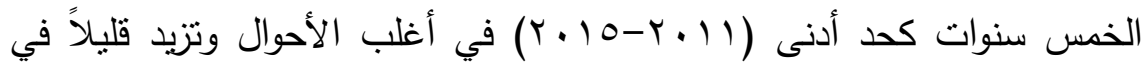
أحيان أخرى. وتتثل هذه الجهات: 
- وكالة الوزارة للتخطيط والمعلومات بوزارة التعليم العالي بالمملكة العربية

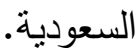
- التقارير السنوية لمؤسسة النقد العربي السعودي (فيما يخص مؤشرات الإنفاق) - وزارة الاقتصاد والتخطيط (فيما يخص الاستراتيجية الوطنية للتحول لمجتمع (المعرفة) - بيانات وزارة المالية (فيما يخص الإنفاق الحكومي) - مصلحة الإحصاءات العامة والمعلومات (فيما يخص نصيب الفرد من الناتج المحلي)

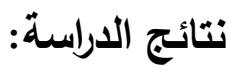

(1) قبول نموذج التوجهات الاستراتيجية (فروض الاراسة) تشير نتائج تحليل الاستبيان قبول النموذج المقترح للتوجهات الاستراتيجية للجامعات الحكومية السعودية حيث يثير الجدول رقم (Y) إلى قبول كل المؤشرات المقترحة لقراءة التوجهات السياسية والاقتصادية والمالية والاجتماعية والثقافية، وكان أكثر المؤشرات تأثثراً تتوع البرامج والتخصصات ونمو عدد

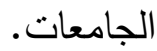




\begin{tabular}{|c|c|c|c|}
\hline \multicolumn{4}{|c|}{ 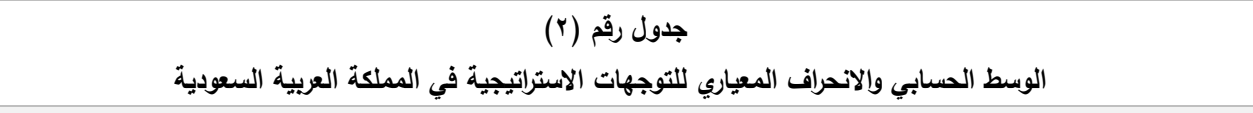 } \\
\hline \multicolumn{4}{|c|}{ م. ( ) مجموعة مؤشرات التوجهات الاستراتيجية في المملكة العربية السعودية } \\
\hline الانحراف المعياري & الوسط الحسابي & \multicolumn{2}{|c|}{ 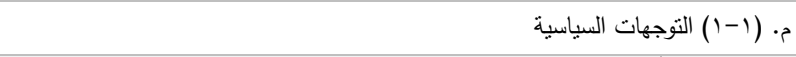 } \\
\hline .67685 & 4.3793 & |الاستراتيجية الوطنية للتحول إلى مجتمع المعرفة & $(1-1-1)$ \\
\hline .50123 & 4.4138 & 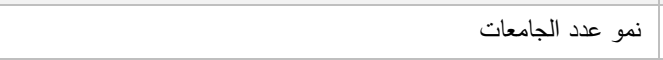 & $(2-1-1)$ \\
\hline .74278 & 3.8621 & نمو عدد الجامعات لكل مليون نسمة & $(3-1-1)$ \\
\hline .61987 & 4.2069 & 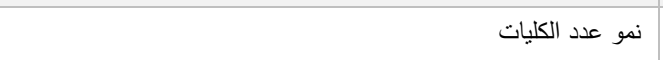 & $(4-1-1)$ \\
\hline .75266 & 4.0690 & توزيع الجامعات حسب المنطق الإدارية ومدى تناسب عددها مع عدد & $(5-1-1)$ \\
\hline الانحراف المعياري & الوسط الحسابي & \multicolumn{2}{|c|}{ م• (1-1) التوجهات الاقتصادية والمالية ( } \\
\hline .82001 & 4.3793 & الاستراتيجية الوطنية بعيدة المدى OY ·rم. & $(1-2-1)$ \\
\hline .50612 & 4.4483 & تنوع البرامج والتخصصات & $(2-2-1)$ \\
\hline .71231 & 4.3103 & نمو الإنفاق على التعليم العالي ل & $(3-2-1)$ \\
\hline .72431 & 4.1034 & نسبة الإنفاق الحكومي على التعليم العالي من إجمالي الإنفاق الحكومي & $(4-2-1)$ \\
\hline .61987 & 4.2069 & معدل الإنفاق الحكومي على الطالب في مؤسسات التطليم العالي & $(5-2-1)$ \\
\hline .82301 & 3.9655 & المحلي الإجمالي. معدل الإنفاق الحكومي على الطالب كنسبة من نصيب الفرد من الناتج & $(6-2-1)$ \\
\hline .65841 & 4.1724 & والإنفاق الحكومي على التعليم العالي كنسبة من الناتج المحلي الإجمالي & $(7-2-1)$ \\
\hline .94426 & 3.9655 & من الإنفاتج الحكومي على الطالب في التعليم العالي كنسبة من نصيب الفرد & $(8-2-1)$ \\
\hline الانحراف المعياري & الوسط الحسابي & \multicolumn{2}{|c|}{ م· (1-r) التوجهات الاجتماعية والثقافية } \\
\hline .30993 & 4.1034 & | نمو الطلاب المستجدين وتوزيعهم النسبي حسب الجنس & $(1-3-1)$ \\
\hline .55709 & 3.8966 & نمو أعداد الطلاب المستجدين حسب نوع الدراسة (منتظم / منتس) & $(2-3-1)$ \\
\hline .90156 & 3.7931 & نمو أعداد الطلاب المستجدين حسب جهة الدراسة (حكومي/ أهلي) & $(3-3-1)$ \\
\hline .94816 & 3.4483 & نمو أعداد الطلاب المستجدين حسب الجنسية & $(4-3-1)$ \\
\hline .81851 & 3.7931 & التوزيع النسبي للطلاب المستجدين حسب المسنوى التطليمي & $(5-3-1)$ \\
\hline .77205 & 3.8966 & التوزيع النسبي للطلاب المستجدين حسب المجال النعليمي & $(6-3-1)$ \\
\hline .84515 & 4.0000 & التوزيع النسبي للطلاب المستجدين حسب المناطق الإدارية & $(7-3-1)$ \\
\hline
\end{tabular}


(Y) قبول المؤثرات المقترحة لقراءة توجهات وزارة التعليم العالي بالمملكة. تثنير نتائج تحليل الاستبيان الجدول رقم (r) إلى قبول كل المؤشرات المقترحة

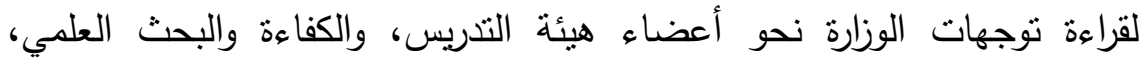
والطلاب الدارسين بالخارج، والتوجهات المعتمدة من قبل الوزات التواة وكان أكثر المؤشرات تأثثراً توجهات الوزارة نحو الجودة والتوسع والتمايز •

\begin{tabular}{|c|c|c|c|}
\hline \multicolumn{4}{|c|}{ الوسط الحسابي والانحراف المعياري للتوجهات الاستراتيجية في وزارة التعليم العالي بالمملكة } \\
\hline \multicolumn{4}{|c|}{ 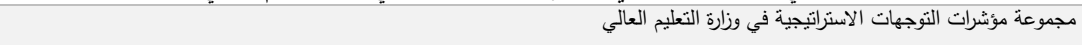 } \\
\hline 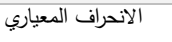 & 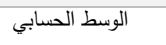 & \multicolumn{2}{|c|}{ م· (ץ-1) مؤثرات أعضاء هيئة التنريس } \\
\hline .58089 & 4.1379 & نمو أعداد أعضاء هيئة التنريس حسب الجنس & $(1-1-2)$ \\
\hline .75266 & 3.9310 & نمو أعداد أعضاء هيئة التنريس حسب الجنس والجنسية & $(2-1-2)$ \\
\hline .75266 & 3.9310 & التوزيع النسبي لأعضاء هيئة النتريس حسب الجنسية & (3-1-2) \\
\hline .72431 & 3.8966 & التوزيع النسبي لأعضاء هيئة التنريس حسب المناطق الإدارية & (4-1-2) \\
\hline .75266 & 3.9310 & التوزيع النسبي لأعضاء هيئة التنريس حسب المستوى التعليمي & $(5-1-2)$ \\
\hline .90565 & 3.9655 & دليل النكافؤ & $(6-1-2)$ \\
\hline 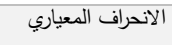 & 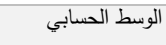 & \multicolumn{2}{|c|}{ 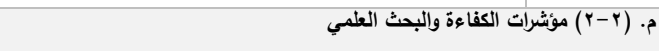 } \\
\hline 1.15648 & 3.8621 & نسبة الطالب إلى عضو هيئة التدريس & $(1-2-2)$ \\
\hline 1.01710 & 3.9655 & أعضاء هيئة التنريسة التنريس الذين يحملون الدكتوراه إلى إجمالي & $(2-2-2)$ \\
\hline 1.16179 & 3.7241 & 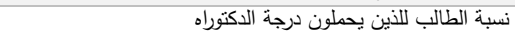 & $(3-2-2)$ \\
\hline 1.06674 & 4.0690 & نمو الطلاب في مرحلة الماجستير والدكتوراه & $(4-2-2)$ \\
\hline .88918 & 4.1724 & لمو الإنتاج البحثي حسب قاعدة ISI/SCOPUS & $(5-2-2)$ \\
\hline .50855 & 4.4828 & الإنفاق على البحث العلمي & $(6-2-2)$ \\
\hline الانحراف المعياري & 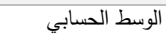 & \multicolumn{2}{|c|}{ م. (ץ- مَ) مؤشرات الطلاب الدارسين بالخارج } \\
\hline 1.01346 & 3.7931 & نمو أعداد الدراسين بالخارج حسب الجنس & $(1-3-2)$ \\
\hline 1.40197 & 3.5862 & نوم أعداد الدراسين بالخارج حسب فئة الابتعاث & $(2-3-2)$ \\
\hline 1.32613 & 3.4828 & نمو أعداد الدارسين بالخارج حسب مستوى التعليم & (3-3-2) \\
\hline .94946 & 3.4828 & التزيع النسبي للطلاب الدارسين في الخارج حسب مجال التعليم & $(4-3-2)$ \\
\hline 66027 & 3.6897 & دليل تكافؤ الجنس لطلاب الخارج & $(5-3-2)$ \\
\hline الانحراف المعياري & الوسط الحسابي & \multicolumn{2}{|c|}{ م· (ץ- (؟) توجهات معتمدة } \\
\hline 68229 & 4.5862 & التوسع & (1-4-2) \\
\hline .41225 & 4.7931 & الجودة & (2-4-2) \\
\hline .50123 & 4.5862 & الثمايز & (3-4-2) \\
\hline
\end{tabular}


(r) قبول المؤثرات المقترحة لقراءة توجهات المنطقة الشرقية

تشير نتائج تحليل الاستبيان الجدول رقم (ع) إلى قبول كل المؤشرات المقترحة لقراءة توجهات المنطقة الثرقية والأحساء وكان أكثر المؤشرات تأثيراً عدد سكان إنئن المنطقة الثرقية والأحساء.

\begin{tabular}{|c|c|c|c|}
\hline \multicolumn{4}{|c|}{ 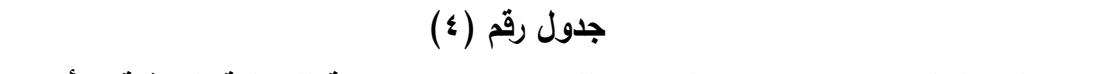 } \\
\hline \multicolumn{4}{|c|}{ مجموعة مؤشرات التوجهات الاستراتيجية في المنطقة الثرقية والأحساء } \\
\hline 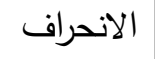 & 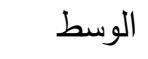 & التوجهات الاستراتيجية في المنطقة الثرقية & 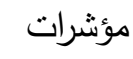 \\
\hline 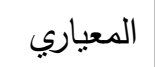 & الحسابي & & والأحساء \\
\hline .78627 & 4.2414 & عدد سكان المنطقة الثرقية ومحافظة الأحساء & $(1-3)$ \\
\hline .74278 & 4.1379 & تقديرات السكان لسنوات الخطةالاستراتيجية & $(2-3)$ \\
\hline .78446 & 4.1538 & نوع القطاع الآت الاقتصادية بالمنطقة الثرقية حسب الإدارية & $(3-3)$ \\
\hline .82301 & 4.0345 & المنشآت الاقتصادية حسب فئة حجم المشتغلين & $(4-3)$ \\
\hline .88362 & 3.9310 & توجهات خاصة بجامعة الملك فيصل & $(5-3)$ \\
\hline .82301 & 4.0345 & توجهات خاصة بالتتافسية & $(6-3)$ \\
\hline
\end{tabular}

(؛ ) قبول كافة المؤثرات المقترحة لقراءة توجهات التميز في الجامعات تشير نتائج تحليل الاستبيان الجدول رقم (ع) إلى تطابق مؤشري العراقة والقدم والبيئة والثقافة الموروثة في قيمة الوسط الحسابي، بينما كان مؤشر التصنيفات

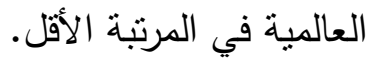




\begin{tabular}{|c|c|c|c|}
\hline \multicolumn{4}{|c|}{ الوسط الصسابي والانحراف المعياري للتوجهات الم رقم (ه) } \\
\hline \multicolumn{4}{|c|}{ مجموعة مؤشرات التوجهات الاستراتيجية للتميز بالجامعات } \\
\hline الانحراف المعياري & الوسط الحسابي & للتميز في الجامعات & 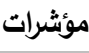 \\
\hline .49380 & 4.3793 & العراقة والقدم & (1-4) \\
\hline .67685 & 4.3793 & البيئة والثقافة الموروثة & $(2-4)$ \\
\hline .99753 & 3.9310 & معايير التصنيف العالمي & (3-4) \\
\hline
\end{tabular}

(ه) قبول كافة المؤثرات المقترحة لقراءة التوجهات الاستراتيجية العالمية

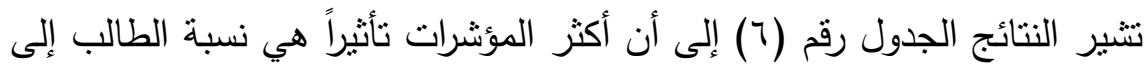

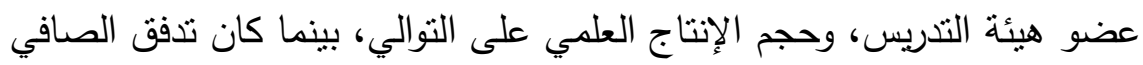
للطلاب الدوليين والتوزيع النسبي للحراك الطلابي الأقل تأثيراً.

\begin{tabular}{|c|c|c|c|}
\hline \multicolumn{4}{|c|}{ 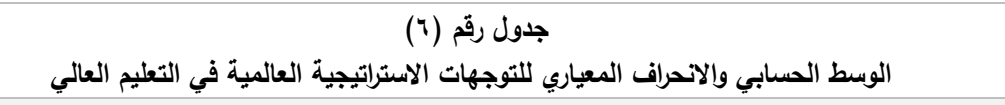 } \\
\hline \multicolumn{4}{|c|}{ مجموعة مؤشرات التوجهات الاستراتيجية العالمية في التعليم العالي } \\
\hline الانحراف المعياري & الوسط الحسابي & \multicolumn{2}{|c|}{ م. (0- 1) مؤشرات الطلاب المقيدين } \\
\hline .68948 & 3.6538 & نسبة الطلاب المقيدين في مستوى التعليم & $(1-1-5)$ \\
\hline .84943 & 3.8077 & 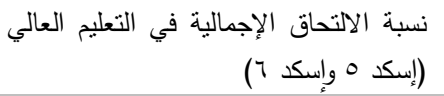 & $(2-1-5)$ \\
\hline .68948 & 3.6538 & بالتعليم العالي الجنس لنسب الالتحاق الإجمالية & $(3-1-5)$ \\
\hline 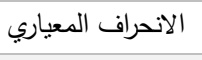 & الوسط الحسابي & \multicolumn{2}{|c|}{ م. (•-r) مؤشرات الحراك الدولي للطلاب } \\
\hline 1.08958 & 3.5172 & التدفق الصافي للطلاب الدوليين & $(1-2-5)$ \\
\hline 1.08958 & 3.5172 & 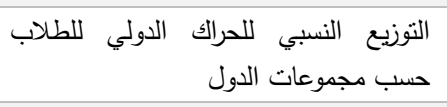 & $(2-2-5)$ \\
\hline الانحراف المعياري & الوسط الحسابي & \multicolumn{2}{|c|}{ م. (•-r- مؤشرات الكفاءة والبحث العلمي } \\
\hline .92182 & 4.2759 & نسبة الطالب إلى عضو هيئة التدريس & $(1-3-5)$ \\
\hline 1.16285 & 4.0690 & حجم الإنتاج العلمي & $(2-3-5)$ \\
\hline
\end{tabular}


"هي مؤشرات عالمية للتعليم العالي تعتمدها منظمة الأمم المتحدة والتي يرصدها

$$
\text { معهد اليونسكو للإحصاء. }
$$

(†) مستوى التوجهات الاستراتيجية الخارجية الأكثر تأثيراً في بناء التوجهات الاستراتيجية للجامعات الحكومية بالمملكة

يتضح من تحليل نتائج الاستبيان الجدول رقم (V) إلى تساوي المستويات الثلاثة الأولى وهي توجهات المملكة والوزارة والمنطقة الثرقية والأحساء في قوة التأثير على التوجهات الاستراتيجية في الجامعات الحكومية السعودية. بينما كان أقل التوجهات تأثثراً في التوجهات الاستراتيجية الجامعات الحكومية السعودية التوجهات العالمية، وإن كانت هذه التوجهات هي الأقل إلا أنها تنقى ذات تأثير واضح على التوجهات الاستراتيجية للجامعات الحكومية السعودية. جدول رقم (V) الوسط الحسابي والانحراف المعياري لمستويات الاستراتيجية وقوة تأثيرها حسب

\begin{tabular}{|c|c|c|}
\hline \multicolumn{3}{|r|}{ العينة } \\
\hline الانحراف المعياري & الوسط الحسابي & التوجهات الاستراتيجية \\
\hline$\cdot v \cdot 7$ & $\varepsilon . \cdot v_{0}$ & مجموعة مؤشرات المملكة العربية السعودية \\
\hline$\cdot . \wedge$ ^A & $\varepsilon . . \uparrow \wedge$ & مجموعة مؤشرات وزارة التعليم العالي \\
\hline$\cdot . \wedge \cdot v$ & $\varepsilon \ldots \wedge \wedge$ & والاحموعة \\
\hline .Vrr & S.YYq & مجموعة مؤشرات التميز في الجامعات \\
\hline .901 & r.vq & مجموعة المؤشرات العالمية \\
\hline
\end{tabular}

كما تشير نتائج التحليل الإجمالية الى أن أكثر المؤشرات تأثنراً في نموذج

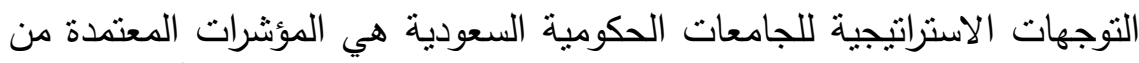

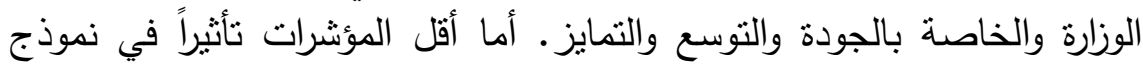


التوجهات هي: التدفق الدولي للطلاب الدوليين والتوزيع النسبي للحراك الدولي

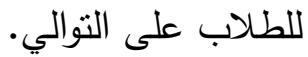

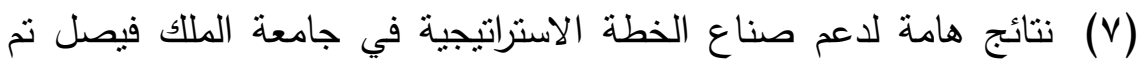

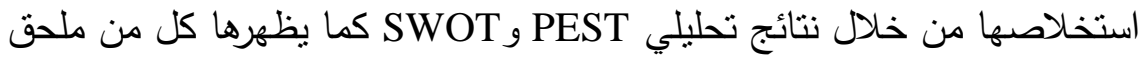
رقم (l) وملحق رقم (Y) على الترتيب. خامسا: توصيات الدراسة

ا ـ توصيات خاصة بالجامعات الحكومية بالمملكة - ضرورة الاهتمام باشتقاق التوجهات الاستراتيجية بدقة حيث أكدت الدراسة على بلى بادماته حقيقة أن الوقوف على التوجهات الاستراتيجية بدقة بمنح الجامعات الحكومية قدرات عالية للنخطيط الناجح لمستقبلها، ويمكنها من أدواتها لتحقيق تفوقها في المستقبل.

- ضرورة استتباط التوجهات الاستراتيجية للجامعات الحكومية من المؤشرات المعتمدة عالمياً والتي عبر عنها النموذج بعيداً عن الرؤى والاجتهادات الثخصية للقيادات الجامعية والمكلفين بوضع الخطط الاستراتيجية وعدم اللجوء للاجتهاد إلا في حدود ضيقة جداً. - - ضرورة الاهتمام بالتوجهات العالمية في التعليم العالي. فبالرغم من أهميتها في تصنيف المملكة الحاضنة للجامعات الحكومية عالمياً إلا أن نتائج الدراسة أنشارت إلى أن هذه المؤشرات تعد الأقل تأثنراً في التوجهات الاستراتيجية للجامعات الحكومية السعودية. - ضرورة توجيه استثمار الجامعات الحكومية نحو تحقيق مؤشرات الوزارة المنمنتة في الجودة والتوسع والتمايز، وذللك بسرعة الحصول على الاعتمادات العالمية في الجودة، وتغطية جميع الثرائح المجتمعية المستهذفة من خلال التوسع في القبول، وتحقيق التميز للجامعات الحكومية داخل المملكة وخارجها. 
- ضرورة الاهتمام بتوطين الدراسات العليا وسعودتها لنقليل النزوح الكبير للطلاب نحو الخارج لإكمال دراساتهم خاصة وأن المملكة تمنلك إمكانيات تحقيق ذللك، وهذا ما أثنارت إليه الدراسة حيث أن مؤثري التدفق الدولي للطلاب والتوزيع النسبي للحراك الدولي هما الأقل تأثيراً على التوجهات الاستراتيجية

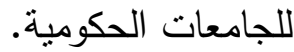

\section{r - توصيات خاصة بجامعة الملك فيصل}

- التركيز عل متطلبات المنطقة الإدارية التي تعمل فيها جامعة الملك فيصل. - التركيز على تميز الجامعة بشكل يضمن لها صدارة تتناسب مع عراقتها وقدمها بالنسبة للجامعات الأخرى. - افتتاح كليات جديدة داخل الحرم الجامعي أو خارجه ، للاستفادة من التوجه الحكومي لتغطية كافة المجالات لتلبية منطلبات المرحلة وخطط التتمية. - التزكيز على التطور النوعي في الخدمات المقدمة للطالب، خاصة تلك التي تخص التجهيزات التعليمية، وبناء مناخ تعليمي مناسب، يساعد على تقديم خدمة منميزة. - استقطاب المتميزين من الذين أتموا دراستهم على حسابهم الخاص من

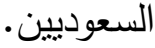
- دعم وتتجيع وتحفيز أعضاء هيئة التدريس على البحث والنشر في مجلات علمية معتبرة.

- التأكيد على تطوبر الثراكة المجتمعية، باعتبارها الميزة التتافية التي تسعى الجامعة لنطويرها. - تطوير برامج تخدم قطاع البترول والصناعات التي تقوم على خدمته. 
- سرعة إنجاز الاعتماد المؤسسي للجامعة. - ترغيب الطالبات بمزيد من المحفزات في البرامج التي لا تلقى قبولاً لديهن.

\section{مراجع الدراسة}

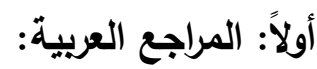

1-الغالبي، طاهر محسن، إدريس، وائل محمد، (9 . . ب)، الإدارة الاستراتيجية منظور منهجي متكامل، الطبعة الثانية، دار وائل للنشر والتوزيع، عمان، الأردن.

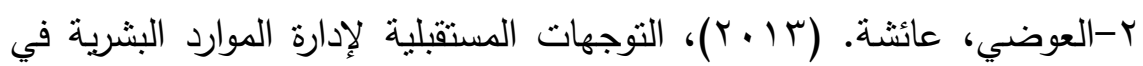
فروع الجامعات العالمية في دولة الإمارات العربية المتحدة من وجهة نظر رؤساء تلك الجامعات، دراسات عربية في التربية وعلم النفس ASEP، العدد بع، ص صد ص ص $1 \cdot 7-9$ r-التقرير السنوي الحادي والخمسون، (10 • ب)، التقرير الدوري، مؤسسة النقد السعودي، المملكة العربية السعودية. ع-الاستراتيجية الوطنية للتحول لمجتمع المعرفة، (10 • ب)، تحول المملكة إلى مجتمع المعرفة، وزارة الاقتصاد والتخطبط، المملكة العربية السعودية.

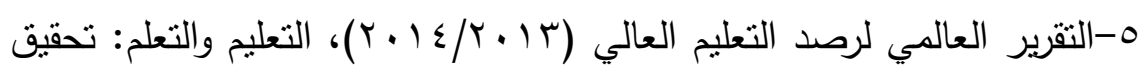
الجودة للجميع، منظمة الأمم المتحدة للتربية والعلم والثقافة، الطبعة الأولى.

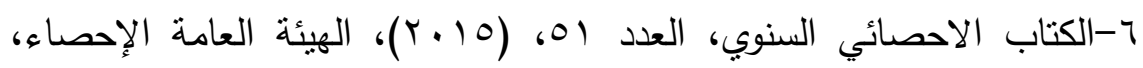
المملكة العربية السعودية. V-ثقرير مرصد التعليم، (0 (Y)، التعليم في المملكة العربية السعودية مؤشرات محلية ومقارنات دولية، وزارة التعليم، المملكة العربية السعودية. 


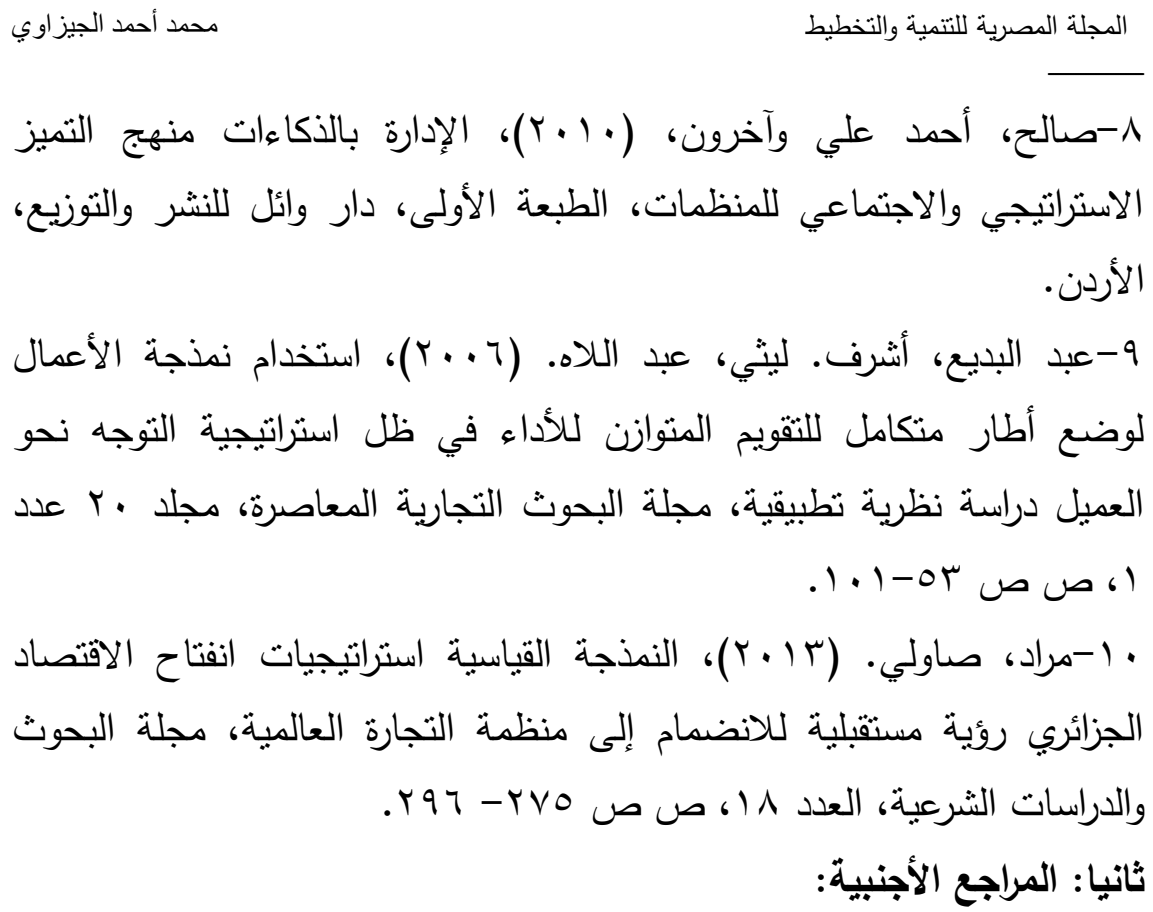

1. Engelsman, Wilco. And Other. (2011), Extending enterprise architecture modelling with business goals and requirement, Enterprise information system, Vol. 5 No. 1 February, pp. 9-36

2. Damij, Nadja. (2007), Business process modelling using diagrammatic and tabular techniques, Business process management journal, Vol. 13 Iss. 1 pp. $70-90$

3. Doomun, Rozive. Jungum, Nevin. (2008), Business process modelling simulation and reengineering: call center, business process management journal, Vol.14 Iss 6 pp. 838-848

4. Francis\&. Mathooko. (2015), Porter's five competitive forces framework and others factors that influence the choice of response strategies adopted by public university in Kenya, International Journal of education management, Vol. 29 Iss 3 pp. 334-354

5. J. Kent Croawford, Jeannette Cabanis, (2011), the Strategic Project Office Second Edition, Brewin Taylor and Francis Group, LLC. 
6. Kilbidge Peter M. (1961), The balance delay problem, Management science, volume8, Issue 1.

7. Liu, Eng\& Ko. (2013), strategic direction of corporate community involvement, J Bus Ethics 115, pp 469-487

8. Morden, Tony. (2007), principles of strategic management, Ashgate publishing limited, England.

9. Niven, Poul R. (2002), Balance scorecard step-by-step, John Wiley\& Sons, Inc.

10.Oregan,\& Ghobadian,. (2004), the importance of capabilities for strategic direction and performance, Management decision, Vol. 42 Iss2 pp. 292-313

11.Peter\& Cetro. (1995), Strategic Management A focus on process, McGraw-Hill publishing company. Villolanga, Blen. (2014), Advances in strategic management, Emerald Group Publishing Limited

12.http://www.unesco.org/

13.https://www.kfu.edu.sa 


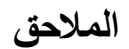

\section{ملحق رقم (1) نتائج تحليل}

\begin{tabular}{|c|c|}
\hline 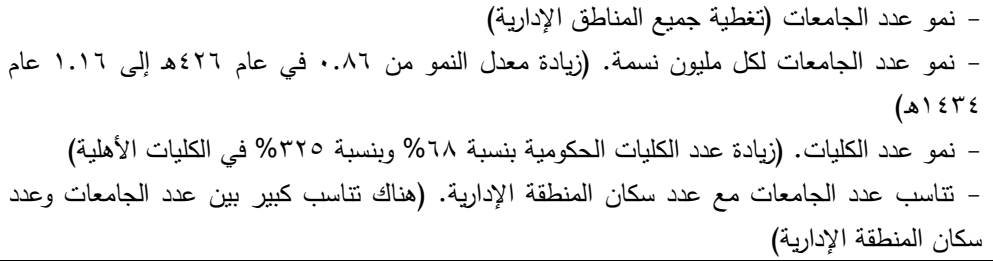 & سياس \\
\hline 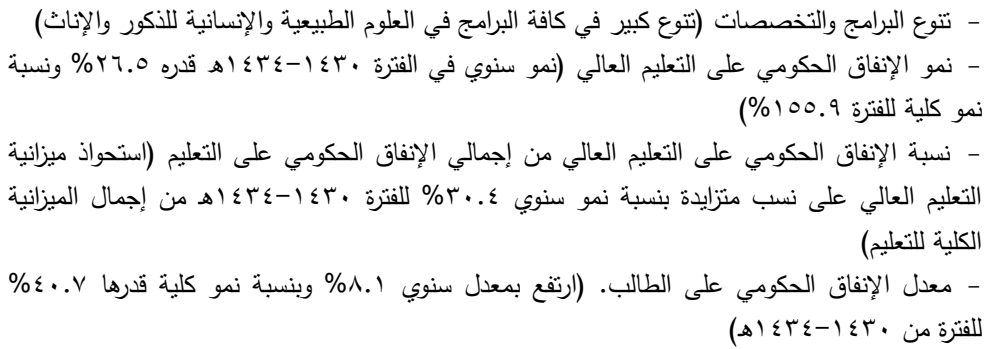 & \\
\hline 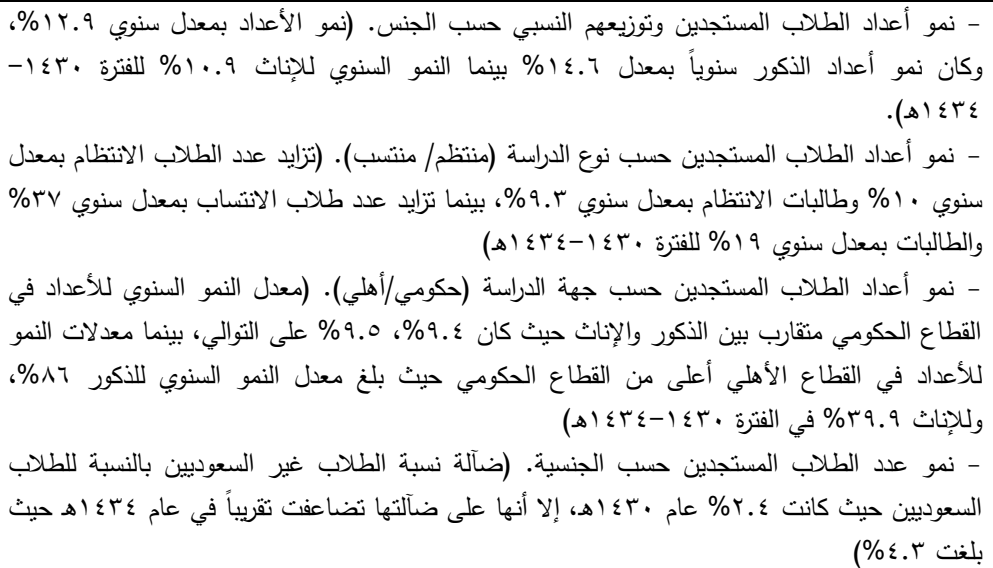 & اجتماعية \\
\hline 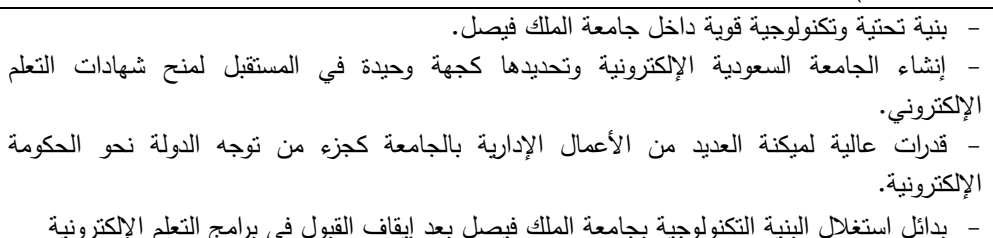 & \\
\hline
\end{tabular}




\section{ملحق رقم (ץ) نتائج تحليل}

\begin{tabular}{|c|c|}
\hline 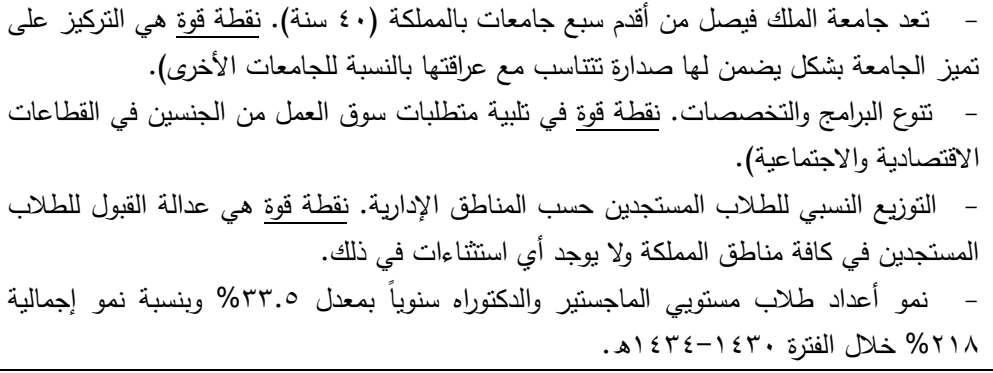 & \\
\hline 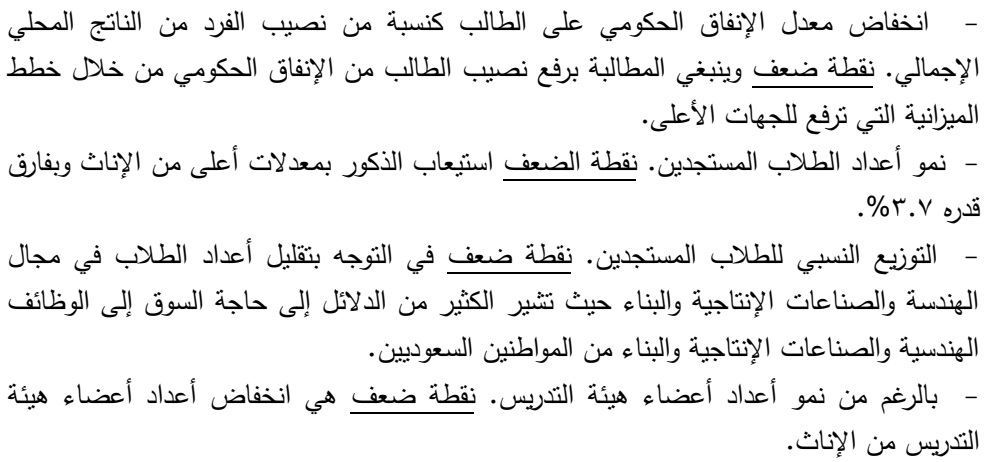 & \\
\hline 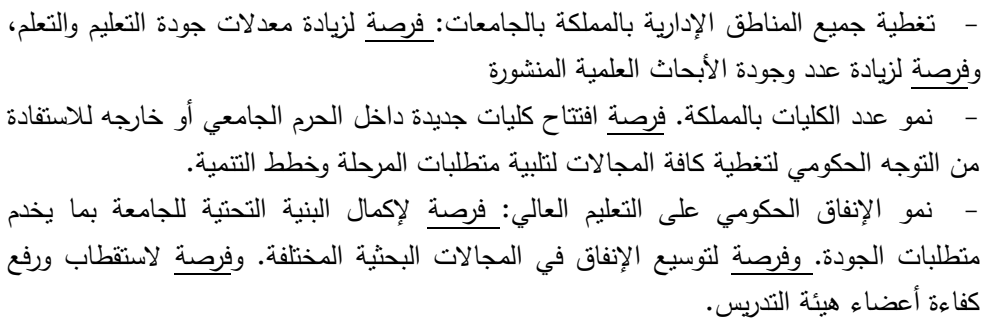 & الفرصر \\
\hline 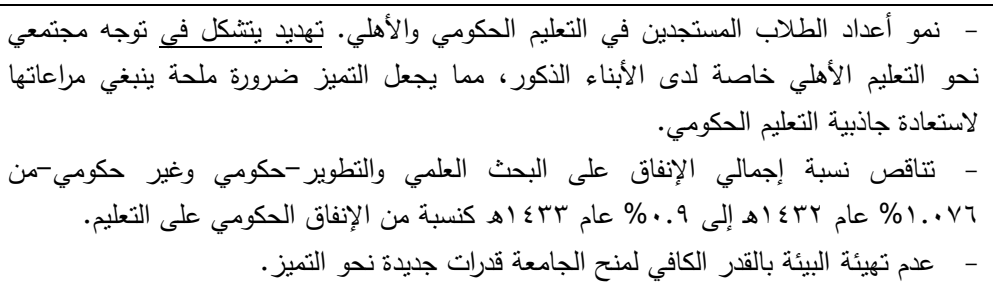 & التهديدات \\
\hline
\end{tabular}

